\title{
APROXIMACIÓN SOCIAL A LA ESTRUCTURA DEL CAPI- TAL. JEREZ DE LA FRONTERA (1750-1790)
}

\author{
Jesús Manuel González Beltrán. \\ Universidad de Cádiz.
}

\section{$\underline{R E S U M E N}$}

Este estudio pretende un análisis de la estructura del capital en Jerez de la Frontera (Cádiz) a finales del siglo XVIII, tanto desde una vertiente económica como social. Para ello se ha utilizado como fuente documental los inventarios post-mortem, obteniéndose una rica visión en matices económicos y profesionales de la sociedad de tipo rural de fines de la Edad Modema.

Palabras claves: Inventario "post mortem", siglo XVIll, capital, grupos sociales.

\section{ABSTRACT}

The objetive of this paper is to analyze the capital structure in Jerez de la Frontera (Cádiz) at the end of XVIII ${ }^{\text {th }}$ century, from economical as well as social points of view. "Post mortem" inventories have been used as the main documentary source, through which, we can tinge a very rich view of economic and professional behaviors of rural society at the end of Modern Age.

KeyWords: Inventory "post mortem", XVIII century, capital, social group.

\section{Cuestiones metodológicas}

En los últimos años está teniendo un importante desarrollo la denominada Historia Social, aunque se sustente sobre la base deslizante de una controvertida falta de definición motivada por la múltiple funcionalidad a la que se ve sometida 
esta tendencia historiográfica'. Desde una aplicación como pretendido sucedáneo renovado de la añeja idea de la Historia total hasta el pormenorizado análisis psicológico tienen cabida en el amplio abanico de posibilidades de utilización de la Historia Social2. Sin olvidar el uso de lo Social como un simple adjetivo que viene a sustituir o a contraponerse a otros apelativos clásicos de la Historia como Política, Institucional o Económica. Desde esta última perspectiva lo significativo sería el envoltotio, cayendo en el entramado de las corrientes o modas, y no el propio sujeto del estudio. Contrarios a esta tendencia, entendemos la Historia Social como una vía de acercamiento a dicho sujeto, que tenemos claro que es la Sociedad, y con unos objetivos bien definidos: plantear interpretaciones tanto sobre los mecanismos de pervivencia y reproducción del sistema social como sobre los factores de cambio o alteración del mismo3. Estos fines generales no son siempre fáciles de alcanzar, sobre todo cuando la sociedad a observar presenta un nivel medio o alto de desarrollo, con lo que ello significa de complejidad en las relaciones y mezcolanza de intereses. Se precisan, pues, acercamientos parciales que vayan desbrozando el bosque, lo cual posibilitará futuras interpretaciones globales. En esta línea de previas aproximaciones se enmarca la presente investigación sobre los aspectos sociales de la estructura del capital en Jerez de la Frontera a fines del siglo XVIII.

La centuria dieciochesca, y especialmente su segunda mita, constituye un marco temporal privilegiado si se quieren observar las fricciones producidas en el sistema social por la confrontación pervivencias-cambios. Y, sobre todo, como ha señalado el prof. Bernal ${ }^{4}$, si los objetivos que se persiguen consisten en descubrir aspectos sociales tan destacados, y no por ello mejor conocidos, tales como la transformación de la nobleza, la formación y actuación de los elementos burgueses, el papel de los artesanos en la vida urbana, la conflictividad campesina, etc.. Por otra parte, la elección de Jerez de la Frontera no es aleatoria. Se trata de uno de los principales centros urbanos andaluces, en el que se conjugan un termino

\footnotetext{
'Sobre la Historia Social y su problemática véanse las diferentes aportaciones recogidas en $L$ 'Fistoire sociale (sources et méthodes). Colloque de L'Ecole Normal Superieure de Saint Cloud, Paris, 1967. Para el caso españoi las ponencias del I Congreso de la Asociación de Historia Social en CASTILLO, Santiago (Coord): La Fistoria Social en España. Actualidad y perspectivas, Madrid, 1991. Del mismo modo, el crítico estado de la cuestión expuesto en las densas primeras páginas de la ponencia de ÁLVAREZ SANTALÓ, L.C. y GARCIA-BAQUERO, A.: "La sociedad española del siglo XVIII: nobleza y burguesía (una revisión historiogtáfica)", en Coloquio Internacional Carlos III y su siglo, Madrid, 1990, Tomo I, pp. 351-386..

"CLAVERO, Bartoloné: "Historia social altomoderna: entre la generalidad y la especialidad", en CASTILLO, S. (Coord.): Op. Cit., pp. 219-228, se hace eco de este dilema.

"Esta metodología aplicada a la historia de la familia en CHACON, Francisco: "La Historia de la familia desde la perspectiva de la Historia Social. Notas para las nuevas propuestas de estudio", en CASTLLLO, S. (Coord.): Op. Cit., pp. 261-266. Sobre la diversidad metodológica empleada en la Historia Social ver el escueto resumen presentado por ÁLVAREZ SANTALÓ, L,C, y GARCÍA-BAQUERO A.: "La sociedad española...", Op. Cit., p. 355.

"BERNAL, Antonio Miguel: "Historia Social: siglo XVIIl", en CASTILLO, S. (Coord.): Op. Cit., pp. $229-245$.
} 
municipal amplísimo, una ingente masa poblacional, una economía agro-ganadera con múltiples matices y su cercanía al monopolio comercial gaditano.

El estudio cuantitativo y cualitativo del capital constituye uno de los métodos más apropiados para aproximarnos al conocimiento y comprensión de la estructura social. A través del análisis de las fortunas, de los bienes que las conforman, podemos plasmar una primigenia agrupación socioeconómica. Del mismo modo, se detectan aspectos esclarecedores del entramado social tales como el origen y cuantía de los diversos ingresos y rentas; las posibilidades de inversión y hacía que sectores productivos se dirigen; las necesidades financieras de las distintas actividades económicas o negocios; el papel de los préstamos interpersonales como elemento de cohesión y regulador social; la capacidad y las líneas básicas del consumo, revelándose en ellas las tendencias de atesoramiento, suntuosidad, ostentación, cultura y devoción religiosa características de cada sector social; $\mathrm{y}$, de forma concluyente, obtenemos una visión diáfana tanto de los modos como de los niveles de vida de las personas y grupos examinados.

La fuente documental más apropiada para el estudio de los capitales, de las fortunas, la constituyen los inventarios post mortem. Su uso, ligado al general de la documentación notarial, viene siendo corriente por los historiadores franceses desde hace más de tres décadas ${ }^{5}$, cuyo ejemplo ha sido seguido, con el resultado de escasos pero excelentes trabajos, por la historiografía española ${ }^{6}$. Diversos

\footnotetext{
"El estudio pionero se debe a DAUMARD, A.: Le bourgeoisie parsienne de 1815 a 1848, París, 1963. A éste le siguen los de IBARROLA, J.: Structure sociale el fortune mobiliere et inmobiliere a Grenoble en 1847, París, 1965; el de propio DAUMARD, A. (y otros): Les fortunes françaises au XIX siécle, Paris - La Haya, 1973; y el aportado por LEON, P.: Geographie de la fortune et structures sociales $a$ Lyon au XLX siécle (1815-1914), Lyon, 1974. Ahora biel, como indica ÁLVAREZ PANTOJA, M José: "Una fuente para la historia agraria entre el antiguo y el nuevo régimen: los documentos de bienes post mortem", en Archivo Hispalense, 193-194 (1981), pp. 467-486, en concreto en las pp. 469-470, los historiadores franceses, especialmente los que estudian el siglo XIX, han utilizado una fuente fiscal denominada registro de sucesión de bienes por defunción, quedando los inventarios post mortem como una fuente de uso complementario.

- En el caso español, el recurso a los protocolos notariales en general, y los inventarios en particular; se debe, sobre todo, a la iniciativa del profesor Eiras Roel. Asi, una primera aproximación a la utilidad de los inventarios en EIRAS A. y VILLARES, R.: "Información serial de inventarios post mortem. Área compostelana, 1675-1700", en Actas de las I Jornadas de Metodologia Aplicada de las Ciencias Históricas, III, Santiago, 1975, pp. 183-202. En el II Coloquio de Metodologia Histórica Aplicada, Santiago, 1982, encontramos las aportaciones de PÉREZ GARCÍA, J.M.: "Los inventarios post mortem como indicadores de la riqueza ganadera. Galicia Oecidental (1600-1669)" y de BENNASSAR, B.: "Los inventarios post mortem y la historia de las mentalidades", pp. 139-146. Para el átea andaluza destacaremos los trabajos de ÁLVAREZ SANTALÓ, L.C. y GARCÍA-BAQUERO, A.: "Funcionalidad del capital andaluz en vísperas de la primera industrialización", Estudios Regionales, 5 (enero-junio 1980), pp. 101-131; "La nobleza titulada en Sevilla, 1700-1834 (aportación al estudio de sus niveles de vida y fortuna)", Historia. Instituciones. Documentos, Separata independiente, Sevilla, 1981, pp. 1-44; y la monografía de SÁNCHEZ LORA, José Luis: Capital y conflictividad social en el campo andaluz. Morón de la Frontera (1670-1800), Sevilla, 1997.
} 
autores se han ocupado ya de plantear la metodología a seguir en el tratamiento de los inventarios post mortem, así como a describir formalmente este tipo de documento notarial?. Ello nos permitirá ser bastante conciso en estos aspectos.

Hay diversa documentación notarial que en el siglo XVIII hace referencia, directa o indirectamente, a los bienes que poseen los particulares: escrituras de dote o de capital aportados al matrimonio ${ }^{8}$, obligaciones de fianza, resguardo de deudas, fundación de vínculos y capellanías, testamentos, etc..., pero, como ya hemos dicho, la fuente más completa la conforman los inventarios y particiones de bienes. Aunque, generalmente, se habla de inventarios, muchos notarios dan a este tipo documental la denominación de partición, ya que ésta, la distribución de los bienes del difunto entre los herederos, es el objetivo final del previo inventario.

Se trata de una fuente completa en un doble sentido, primero, al hacer mención del conjunto de los bienes o de la mayor parte de ellos y, segundo, al valorarlos de forma más o menos individualizada. En relación con lo que acabamos de enunciar, hay que señalar, como defecto de la fuente, que determinadas propiedades y bienes no se incluyen, sistemáticamente, en los inventarios. Unas por su especial carácter jurídico, como las vinculadas, cuya propiedad no pertenecía al difunto, tan sólo su usufructo, los beneficios que pudieran reportar; o el lecho cotidiano, especie de ajuar de cama, incluido o no en la dote, que, sin describirse ni computarse entre los efectos a repartir, casi siempre se otorga a la viuda. Y otras por su escasa significación y mínimo valor, lo que ocurre, en muchos casos, con la ropa y enseres domésticos. Del mismo modo, cuando los herederos muestran una gran conformidad con las disposiciones del finado, suele abusar el documento de los aprecios globales, llegándose a obviar la evaluación de los bienes cuando se da un acuerdo previo entre los beneficiarios de la herencia para su reparto.

\footnotetext{
' Con carácter general EIRAS A. y VILLARES, R.: "Información serial de inventarios...". La metodología a seguir en el estudio de sectores sociales relacionados con el mundo rural en ÁLVAREZ SAN'TALÓ, L.C. y GARCIA-BAQUERO, A.: "Los inventarios post mortem como fuente para la historia agraria del Antiguo Régimen", en Actas del II Coloqulo de Historia de Andalucia. Andalucia Moderna, Córdoba, 1983, Vol. I, pp. 137-149; PEREIRA, José Luis y RODRÍGUEZ CANCHO, Miguel: "Inventarios post mortem y riqueza campesina en Extremadura. Aproximación metodológica", en Norba, 4 (1983), pp. 351-359; y ÁLVAREZ PANTOJA, Ma Josê: "Una fuente para,.,". En relación con el estudio de las aligarquías urbanas, y aportando una completa descripción del tipo documental, ARANDA PÉREZ, Francisco J.: "Prosopografia y particiones de bienes: una propuesta metodológica para el estudio de las oligarquías urbanas castellanas en la Edad Moderna", en Cuadernos de Historia Moderna, 12 (1991), pp. 259-276.

"Sobre las dotes dos aportaciones incluidas en las Actas del II Coloquio de Metodología Histórica Aplicada, una de RODRIGUEZ SÁNCHEZ, A.: "Las cartas de dote en Extramadura", Vol. I, pp. 165176, y la otra de BURGO LÓPEZ, $\mathrm{M}^{\mathrm{a}} \mathrm{C}$.: "Niveles sociales y relaciones matrimoniales en Santiago y su comarca (1640-1750) a través de las escrituras de dote", Vol. I, pp. 177-199.
} 
La estructura del documento es ya bastante conocida. En primer lugar habría que decir que se trata de una escritura notarial compleja, que puede incluir en su seno otras escrituras y expedientes diversos, la cual podemos dividir en tres bloques, no siempre todos presentes. El primer apartado lo constituye una copia del testamento, codicilo, ultima voluntad o cualquier disposición o acuerdo que regule o pueda incidir en la formación del inventario y posterior partición de los bienes. De esta parte se obtienen datos familiares, sociales y económicos del difunto. Destacar las alusiones a la dote aportada por la mujer, el capital inicial llevado al matrimonio por el marido, las herencias o legados recibidos durante la vida conyugal, las deudas reconocidas y las cantidades que, por distintas razones, se han entregado a los hijos. Un segundo bloque lo conforma el inventario en sí, en el cual encontramos, precedido o no de las relaciones individualizadas de los aprecios de tasadores y peritos, el cuerpo de hacienda o de caudal más o menos pormenorizado en distintas partidas (casas, tierras, alhajas, ropa, muebles, ganado, granos y otros productos, pertrechos agrícolas o de otras actividades, rentas, deudas a favor, etc...). A continuación, quedan recogidas las diferentes bajas generales que afectan al cuerpo de bienes (aportaciones personales de los cónyuges al matrimonio, deudas en contra, costes del entierro y funeral, mandas o donaciones y, por supuesto, los gastos originados por la propia realización del inventario). Un último apartado se dedica a la adjudicación, en diferentes lotes, de los bienes a los herederos, es la partición definitiva. Todo este proceso recogido por el escribano se ha llevado a cabo con la intervención de alguna autoridad, preferentemente el alcalde mayor, del contador o contadores especificamente designados al efecto y de los albaceas señalados en el testamento, junto a uno o varios curadores ante la existencia de menores entre los beneficiarios. Señalar, finalmente, que, en un porcentaje alto de casos, la formación de los inventarios post mortem responde a la falta de acuerdo entre los herederos, lo cual redunda en una mayor fiabilidad de los datos aportados, ya que nadie quiere salir perjudicado en la distribución de la herencia por cuestiones de sobretasación o infraevaluación. De todos modos, nunca está de más la corroboración de datos usando otras fuentes complementarias ${ }^{9}$. De esta forma escapamos, también, de la posible esclavitud y rigidez en los resultados que el uso de un único tipo documental podría conllevar.

Para esta investigación se ha visto un conjunto de 789 inventarios-particiones, la totalidad de los recogidos en las 22 escribanías de Jerez de la Frontera

\footnotetext{
"Sobre la utilización de otras fuentes, en especial otra documentación notarial y los catastros, ver ARANDA PÉREZ, Francisco J.: "Prosopografia...", p. 276; y PEREIRA, José Luis y RODRÍGUEZ CANCHO, Miguel: "Inventarios post mortem...", p. 354.
} 
durante el periodo $1750-1790^{10}$. Durante este espacio cronológico fallecieron en Jerez un total de 25.686 personas, de las cuales podemos considerar adultas, con más de 20 años, al menos un $45 \%$, lo que significa 11.559 individuos ${ }^{11}$. Por tanto, contamos con los inventarios correspondientes al $6,8 \%$ de estos fallecidos, lo cual podemos considerar como una muestra significativamente representativa ${ }^{12}$. De los 789 inventarios-particiones analizados vamos a trabajar con los datos de 357 , el $45,25 \%$ del total, que son aquellos que presentan una información susceptible de ser tratada informáticamente, aunque 55 de ellos sólo nos indican la posesión de la vivienda. Los 432 inventarios restantes han resultado inservibles para nuestro trabajo. Unos, 391 en concreto, por no contar con evaluación alguna de los bienes, se trataba de particiones sin aprecios previos, o al menos no constan en el documento. Los otros 41 si incluían el evalúo, pero grosso modo, sin aprecios pormenorizados, ni siquiera por partidas amplias.

Contamos pues con 357 inventarios útiles, que no se distribuyen homogéneamente a lo largo del periodo temporal estudiado. Se observa un paulatino incremento de este tipo documental a medida que discurren los años. Así, de la primera década, 1750-1760, tan sólo tenemos 33 inventarios, un 9,25\%; de la segunda 75 , el $21 \%$; hasta 92 , un $25,75 \%$, corresponden a la tercera década; mientras que los años 1780-1790, la cuarta y última década, concentran 157 documentos, el $44 \%$ de la totalidad ${ }^{13}$.

Toda la información que nos proporcionan los 357 inventarios se encuentra almacenada en una base de datos tipo Access, estructurada en diferentes tablas dedicadas a aspectos concretos que nos interesaba individualizar. Las posibilidades de tratamiento, consulta y realización de informes y gráficos que nos permite la mencionada aplicación informática son inmensas, recogiéndose en este estu-

\footnotetext{
${ }^{10}$ Los protocolos de Jerez de la Frontera se encuentran custodiados en el Archivo Municipal de la localidad. El número de legajos que se han consultado ha sido de 256 , siendo los números de legajos extremos el 1413 y el 1797. Contábamos con un catálogo en el que se recogía, entre otros datos, la localizacíon, junto a más tipos de escrituras notariales, de dichos inventarios para el mencionado periodo cronológico. Este catálogo fue realizado en el marco de la OTRI de la Universidad de Cádiz, con fïnanciación del Ayuntamiento de Jerez y bajo mi dirección.

"Estos datos demográficos en BUSTOS RODRÍGUEZ, M. y otros: "La población de la provincia de Cádiz en los siglos XVII y XVIII", en Trocadero. Revista de Historia Moderna y Contemporánea, 2 (1990), pp. 5-71.

12 El artículo de ÁLVAREZ SANTALÓ, L.C. y GARCÍA-BAQUERO, A.: "Funcionalidad del capital...", p. 109, está realizado sobre 627 inventarios del periodo $1780-1834$ y, según los autores, corresponderian al $1,6 \%$ de los adultos fallecidos durante dichos años. Por otra parte, el libro de SÁNCHEZ LORA, José Luis: Capital y conflictividad social..., se basa en 249 inventarios que corresponden a los años 1670-1780.

${ }^{13}$ ÁLVAREZ PANTOJA, Ma José: "Una fuente para...", pp. 474-475, señala como este tipo documental se masifica a partir dal siglo XIX. Como hemos visto, la tendencia al alza proviene ya de finales del XVIII.
} 
dio tan sólo algunas de carácter general, dejando para ulteriores trabajos el análisis de cuestiones más particulares.

\section{Jerez de la Frontera en la segunda mitad del siglo XVIII}

Como indicábamos páginas atrás, el siglo XVIII se nos muestra como un periodo cronológico privilegiado para intentar descubrir transformaciones sociales y económicas que tendrán una gran influencia en el devenir histórico subsiguiente. Los cambios, desarrollados en una sociedad por definición estática, vendrán generados por situaciones conflictivas $\mathrm{y}$, a su vez, provocaran conflictos de diversa índole ${ }^{14}$. Jerez de la Frontera no escapa a esta situación de tensión entre la permanencia de los principios estructurales propios del Antiguo Régimen y la presencia, cada vez más activa, de elementos renovadores y renovados. Para conocer todos estos factores, y para una mejor comprensión de los datos socioeconómicos que sobre los capitales jerezanos plantearemos más adelante, creemos conveniente ofrecer una visión de conjunto de Jerez en la segunda mitad de la centuria dieciochesca. Tarea que llevaremos a cabo manejando diversas fuentes bibliográficas ${ }^{15}$ y documentales, destacando entre éstas ultimas los libros parroquiales, padrones de población, el Catastro de Ensenada, informes sobre el estado de la localidad redactados en los años finales del siglo y expedientes varios.

\footnotetext{
${ }^{14}$ La conflictividad de la segunda mitad del siglo XVIII, en relación con el mundo agrícola, quedar recogidos de manera global, aunque con muchas alusiones al caso andaluz e incluso al particular de Jerez, en ORTEGA, Margarita: La lucha por la tierra en la Corona de Castilla al final del Antiguo Régimen. El expediente de Ley Agraria, Madrid, 1986. También en SÁNCHEZ LORA, José Luis: Capital y conflictividad social..., en concreto las pp. 97-120.

${ }^{15}$ Hasta hace pocos años la bibliografia histórica sobre Jerez de la Frontera era mínima. Ultimamente han visto la imprenta diversos trabajos relacionados, de una u otra forma, con el siglo XVIII jerezano. Así, CARO, D. (Coor.): Historia de Jerez de la Frontera. Tomo 2. El Jerez Moderno y Contemporáneo, Jerez, 1999; ABBOTT, D.R.: The Spanish and the sherry trade: Jerez de la Frontera in the eighteen century, Michigan, 1990; CABRAL CHAMORRO, A.: Fropiedad comunal y reparto de tierras en Cádiz. (siglos XF-XLX), Cádiz, 1995; GONZÁLEZ BELTRÁN, J.M.: Reformismo y administración local en la provincia de Cádiz durante el reinado de Carlos III, Jerez, 1991 y Honor, riqueza y poder. Los veinticuatros de Jerez de la Frontera en el siglo XVIII, Jerez, 1998; JIMÉNEZ BLANCO, J.I.: Privatización y apropiación de tierras municipales en la Baja Andalucía. Jerez de la Frontera, I7501995, Jerez, 1996; RAMOS, A. y MALDONADO, J. (Eds.): El Jerez-Xérès-Sherry en los tres últimos siglos, El Puerto de Santa Maria, 1996; y MALDONADO ROSSO, J.: La formación del capitalismo en el marco del Jerez. De la vitivinicultura tradicional a la agroindustria vinatera moderna (siglos XVIII y XIX), Madrid, 1999.
} 
El término municipal jerezano, con 140.461 hectáreas o, lo que es lo mismo, 314.085 aranzadas $^{16}$, era y es uno de los más amplios de España, tan sólo superado por Lorca y Badajoz. A mediados del siglo XVIII el Catastro de Ensenada señalaba una superficie de $120.475 \mathrm{Ha}$. (269.474 aranzadas), por lo que debido a varios factores (extensión del casco urbano, terrenos ocupados por vías de comunicación y ríos, redondeos en las mediciones de marismas y terrenos montañosos y, por supuesto, algunas ocultaciones) se habían dejado de computar unas 20.000 Ha., aproximadamente un $14,25 \%$ de la superficie total. Este término se encontraba dividido en cuatro jurisdicciones: la propia de Jerez de la Frontera; el despoblado de Tempul, señorio de $38.500 \mathrm{Ha}$. perteneciente al concejo jerezano; el despoblado de Arquillos, señorio de $650 \mathrm{Ha}$. vinculado en los López de Morla; y el despoblado de Pozuela, señorío de $725 \mathrm{Ha}$. vinculado al linaje del marqués de Valhermoso.

Por diversos condicionantes políticoeconómicos los habitantes de este amplísimo territorio se concentraban en un solo núcleo de población, la ciudad de Jerez, la cual, según el Vecindario de Ensenada (1759), tendría 7.078 vecinos más 318 eclesiásticos seculares, en total 7.396. Se trata, por tanto, de una de las mayores agrociudades andaluzas, tan sólo superada dentro del reino sevillano por la propia Sevilla (19.146), Cádiz (9.832) y, escasamente, por Ecija $(7.472)^{17}$. Durante la segunda mitad del siglo XVIII la población de Jerez experimentó un fuerte aumento, aunque la heterogeneidad de los datos de que disponemos, que recogen o vecinos o habitantes, nos impidan establecer concretamente el incremento porcentual. Daremos algunas cifras. Los 7.396 vecinos de 1759 se han convertido en 8.146 según un padrón físcal realizado en 1790 , lo que significa una subida del $0,3 \%$ anual. Pero si hablamos de habitantes, tenemos una población, mayor de 7 años, de 30.076 personas según una encuesta parroquial de 1752, mientras que el Censo de Floridablanca (1787) recoge hasta 36.847 personas mayores de 7 años. Con estos datos el aumento porcentual se eleva al $0,55 \%$ anual. El aumento demográfico es corroborado por los apuntes en los libros parroquiales. Según éstos, en el periodo 1750-1800, resulta positivo el saldo vegetativo con 18.317 individuos ( 50.111 bautizos frente a 31.794 defunciones) ${ }^{18}$.

I6 DIRECCIÓN GENERAL DEL INSTITUTO GEOGRÁFICO Y CATASTRAL: Provincia de Cádiz. Relación de stiperficies de los partidos judiciales y de los términos municipales en $1^{\circ}$ de Abril de 1950 Madrid, 1950, p. 4. Con posterioridad, el término municipal de Jerez ha perdido, con la segregación de San José del Valle, unas 20.000 Ha.. Indicar que la ineđida de superficie empleada en Jerez en el siglo XVIIl es la aranzada, equivalente a 0,4472 hecláreas. Es decir, una hectárea era igual a 2,2361 aranzadas.

"Vecindario de Ensenada, 1759. Vol. III, Madrid, 1991.

18 Los datos demográficos tomados de Archivo Municipal de Jerez de la Frontera (A.M.J.F), Memoranda 4, Fp. 86-95 (año 1752) y pp. 79-85 (año 1787). A.M.J.F., leg. 21 l, exp. 6.320 (año 1790). Y Censo de 1787. Floridablanca. Cádiz, Madrid, 1986. La información parroquial aportada por BUSTOS RODRÍGUEZ, M. y otros: "La población...", pp. 59-71. 
initiva, un más que moderado incremento demográfico que, sin duda, dada la rigidez de la estructura económica de la localidad daria lugar a ciertas tensiones y a conflictos laborales y de orden público estrechamente relacionados.

¿A qué se dedicaba está amplia población jerezana?. Para responder a esta cuestión tomaremos la información que nos ofrece el Catastro de Ensenada. Los libros de familia de dicha encuesta nos indican la existencia de 7.030 personas activas; cantidad en la que no se incluyen a 1.096 hacendados, 69 labradores y otros 987 individuos entre viudas e incapacitados para el trabajo por su avanzada edad o impedimento físico. La distribución de los 7030 nombrados por sectores de actividad cconómica es la siguiente: 4.003 personas, el 56,9\%, en el sector primario; 1.213 individuos, el 17,3\%, en el secundario; y los restantes 1.814 , el $25,8 \%$, corresponden al sector servicios. El libro de lo Personal e Industrial del Catastro, que recoge las retribuciones salariales y los ingresos por actividades industriales y comerciales de estas 7.030 personas, nos permite realizar una estratificación social de los mismos basada en criterios de niveles de renta del trabajo. Para ello, hay que tener en cuenta que, a efectos fiscales, el Catastro establece un número fijo de jornadas de trabajo computables al año, que son 120 para los jornaleros agrícolas, 180 para los trabajadores artesanos y 250 para el servicio doméstico. Y también, que en muchos casos, en especial en las actividades comerciales, to manejamos ingresos reales sino estimaciones realizadas por peritos designados al efecto. Ante tantos inconvenientes un factor positivo, la información nos la ofrece ya tabulada el investigador D. R. Abbott ${ }^{19}$.

Hemos establecido cinco niveles de ingresos, en base al salario o renta media por trabajador o productor de la localidad. Dicha renta media se sitúa en los 915 reales al año, y la hemos redondeado en los 1.000 reales. Un primer nivel englobaría a todos aquellos que no alcanzaban los mencionados 1.000 reales, serían personas que estarian en el límite de la pobreza y la marginación social. El segundo nivel estaría limitado entre una y dos veces el salario medio, 1.000-2.000 reales, en él se englobarian los sectores sociales más populares. Entre los $2.000 \mathrm{y}$ 3.000 reales, dos y tres veces la renta media, se movería el tercer nivel, compuesto por sectores medios de la sociedad sin agobios económicos. Los integrantes del cuarto nivel ingresarían entre 3.000 y 5.000 reales, tres y cinco veces el salario medio, se trata ya de vecinos con un cierto poder adquisitivo lo que les realza socialmente. Por último, en el quinto nivel tenemos a los que ingresan más de 5.000 reales, conformarían la incipiente burguesía jerezana. Hay que señalar que ninguna actividad reportaba una renta media superior a los 10.000 reales.

"ABBOTT, D.R.: The Spanish and the sherry rade.., pp. 319-325. 
En el cuadro 1 podemos comprobar de forma clara los diferentes niveles de renta, por salarios y actividades industriales, en la ciudad de Jerez de la Frontera en la centuria dieciochesca, incluyendo una distribución entre los tres sectores clásicos de la economía.

Cuadro 1. Niveles de ingresos de población activa de Jerez

\begin{tabular}{|l|c|c|c|c|c|}
\hline $\begin{array}{c}\text { Nivel de ingresos } \\
\text { (en reales) }\end{array}$ & $\begin{array}{c}\text { Individuos } \\
\text { por nivel }\end{array}$ & $\begin{array}{c}\% \text { sobre total } \\
\text { de individuos }\end{array}$ & $\begin{array}{c}\% \text { en sector } \\
\text { primario }\end{array}$ & $\begin{array}{c}\% \text { en sector } \\
\text { secundario }\end{array}$ & $\begin{array}{c}\% \text { en sector } \\
\text { terciario }\end{array}$ \\
\hline - de 1.000 & 4.489 & 63,8 & 84,6 & 6,2 & 9,2 \\
De 1.001 a 2.000 & 1.953 & 27,8 & 10,5 & 39,5 & 50,0 \\
De 2.001 a 3.000 & 326 & 4,6 & 0,6 & 40,8 & 58,6 \\
De 3.001 a 5.000 & 180 & 2,6 & 0,0 & 16,1 & 83,9 \\
+de 5001 & 82 & 1,2 & 0,0 & 0,0 & 100,0 \\
\hline
\end{tabular}

La visión de dicho cuadro nos permite comprobar como la casi totalidad de la población, el $91,6 \%$, presenta unos niveles de renta bajísimos. Un $63,8 \%$ por debajo del salario o ingreso medio local y otro $27,8 \%$ percibe entre una y dos veces ese salario medio que, recordemos, era de 915 reales al año. En cuanto a la distribución por sectores económicos podemos observar como la práctica totalidad de los que perciben menos del salario medio pertenecen al sector primario y, más concretamente, a la agricultura. Por el contrario, la mayoría de los que superan los 3.000 reales y los únicos que sobrepasan los 5.000 reales de ingresos son todos del sector terciario. Los dedicados a las actividades artesano-industriales no son mayoritarios en ningún nivel de ingresos, siendo su presencia más destacada en los niveles 2 y 3 , entre $\operatorname{los} 1.000$ y 3.000 reales.

Del análisis de la población activa hay que destacar, especialmente, la amplia presencia de jornaleros agrícolas, los cuales no harán sino incrementarse a lo largo de las ultimas décadas del siglo XVIII. Así, en 1787 el Censo de Floridablanca contabiliza 7.752 jornaleros, lo que significa un aumento del 105\% con respecto a 1752. Los trabajadores del campo terminarán convirtiéndose, tal como reflejan las actas capitulares, en un factor de alteración del orden público cuando las condiciones meteorológicas les impedian trabajar y, por tanto, obtener un jornal.

La existencia de los jornaleros está intimamente relacionada con la estructura agrícola de Jerez, sobre todo con dos aspectos de la misma: la propiedad de la tierra y los usos y formas de explotación de la misma. 
Con respecto al régimen de propiedad hay que señalar, en primer lugar, la gran incidencia del fenómeno de la vinculación. Del total de las 269.474 aranzadas recogidas en el Catastro de Ensenada hasta 233.241, el 86,6\%, se hallaban vinculadas ${ }^{20}$. De ellas, 111.545 aranzadas por ser de propiedad concejil o pública; 89.633 amayorazgadas o vinculadas por particulares; $y 32.063$ pertenecientes a instituciones eclesiásticas. Por otra parte, y en consonancia con el panorama de vinculación expuesto, se detecta una fuerte concentración de la propiedad en pocos individuos o instituciones. A modo de ejemplo, ya hemos hecho mención a las 111.545 aranzadas administradas por el concejo local, pero podemos indicar como 32 de los regidores o caballeros veinticuatros del cabildo poseían 61.884 aranzadas, o las 15.172 medidas pertenecientes a 6 conventos de la localidad. Es decir, solo los 39 propietarios nombrados, y aún faltarían algunos importantes, acaparan el $70 \%$ de toda la superficie del término ${ }^{21}$. El mercado de la tierra se encontraba, por tanto, anquilosado y casi cerrado, provocando tensiones en una época de fuerte expansión agraria. Por otra parte, la concentración de la tierra en pocas manos absentistas daba lugar a un régimen de explotación en el que predominaba la cesión a grandes arrendatarios, por lo que predominaban las grandes explotaciones, muchas veces con tendencia a la infrautilización de la tierra. Ante este panorama no era raro el que se produjese el desabastecimiento de la población en determinados años de pérdida de cosecha o cuando ésta fuera escasa, elemento que viene a tensionar, aun más, la situación de los jornaleros de la localidad.

Si los componentes de los grupos sociales populares eran los más perjudicados por la estructura económica en general y agrícola en particular, hay otros miembros de la sociedad que se benefician de la situación. Estamos hablando de la incipiente burguesía agrícola-comercial, de la nobleza dirigente y del estamento eclesiástico.

Las instituciones de la lglesia en Jerez y sus miembros, que no eran más del $4,5 \%$ de los vecinos, perciben casi una séptima parte de todas las utilidades, rentas, que se generaban por las distintas actividades económicas desarrolladas en la localidad.

\footnotetext{
${ }^{20}$ A.M.J.F., Memoranda 4, pp. 86-95.

${ }^{21}$ Hacemos referencia a los veinticuatros y conventos que poseían más de 500 aranzadas de tierra. Sobre ello GONZÁLEZ BELTRAN, J.M.: Honor, riqueza y poder..., pp. 62-65 y "Patrimonio y rentas de los conventos de Jerez de la Frontera a fines del Antiguo Régimen", en Panfletos y materiales, Trebujena, 1998, pp. 295-314.
} 
Por su parte, la nobleza dirigente jerezana ${ }^{22}$ basaba su posición de privilegio no sólo en sus posesiones, preferentemente tierras, sino también en el control que ejercía sobre los diversos cargos municipales, hacendísticos y militares del municipio.

La burguesía jerezana de la segunda mitad del siglo XVIII, constituida por comerciantes de excedentes agrícolas (vino y trigo), por algunos grandes labradores arrendatarios y por profesionales liberales, es el elemento social dinamizador de la vida política local. Sin plantear una modificación general del status quo, si alentaba la implantación de determinados cambios que, sobre todo en el ámbito económico, promovieran una mayor libertad de acción. Ello va a dar lugar a tensiones y fricciones con la nobleza dirigente tradicional que se reflejan, espesialmente, a través de las elecciones a diputados del común y personero ${ }^{23}$, y en la incoación de sonados pleitos ${ }^{24}$.

Planteada esta aproximación a la realidad socioeconómica de Jerez en la segunda mitad del siglo XVIII, vamos a ver como queda reflejada a través del estudio de los inventarios post mortem.

\section{Estudio global de los capitales inventariados}

Los 357 inventarios útiles que hemos analizado alcanzan un montante total de 42.504.762 reales de vellón, lo que implica un capital medio de 119.061 reales, dato irreal y que aportamos a efectos de interés comparativo. Los extremos van desde un inventario con tan sólo 726 reales a otro con 4.943.223. Este último, perteneciente al comerciante gaditano, pero casado y afincado en Jerez, D. Teodoro José de Roy, es verdaderamente excepcional en el conjunto, duplicando en su monto al que inmediatamente le precede, por lo que, en algunos aspectos, distorsiona ligeramente los datos. Así, si procediéramos a no contabilizarlo, el caudal medio, por ejemplo, descendería hasta los 105.800 reales. Echa esta salvedad y con las prevenciones oportunas, hemos optado por mantenerlo en nuestro estudio global.

\footnotetext{
"La nobleza de Jerez era bastante amplia. A finales del siglo XVIII se contabilizaban 19 títulos de Castilla y 723 familias nobles. VIRUES DE SEGOVIA, Francisco: Epitome de algunas antigüedades, sucesos memorables, magistrados, privilegios, estudios, bibliotecas, varones ilustres en letras y armas, servicios, etc..., de la M.N. y M.L. ciudad de Jerez de la Frontera, Jerez de la Frontera, 1889 (escrito en 1796).

${ }^{2}$ Estos cargos municipales creados en 1766. Aunque en el cabildo en pleno eran minoría los 4 diputados del conún, éstos controlaban órganos tan importantes como la lunta de Propios y Arbitrios y el Pósito. Sobre la aclividad y problemas de estos cargos en Jerez ver GONZÁLEZ BELTRÁN, J.M.: Reformismo y administración...

24 Algunos de los principales pleitos fueron promovidos por los comerciantes de vinos. Sobre ello MALDONADO ROSSO, J.: La formación del capizalismo...
} 
Una primera caracteristica que captamos en el análisis de los inventarios es la disparidad de los activos recogidos, desde menos de 1.000 reales a varios millones. Para una mejor comprensión hemos clasificado los inventarios en 8 grupos, tal como queda reflejado en el cuadro 2 , en el cual indicamos el número de inventarios que conforma cada grupo y el montante de fondos que acumulan.

Cuadro 2. Distribución de los inventarios según activos

\begin{tabular}{|l|c|c|c|c|}
\hline \multicolumn{1}{|c|}{$\begin{array}{c}\text { Activo } \\
\text { (en reales) }\end{array}$} & $\begin{array}{c}\text { número de } \\
\text { inventarios }\end{array}$ & $\begin{array}{c}\text { \% sobre total } \\
\text { inventarios }\end{array}$ & $\begin{array}{c}\text { activo } \\
\text { acumulado }\end{array}$ & $\begin{array}{c}\text { \% sobre total } \\
\text { activos }\end{array}$ \\
\hline De 1 a 10.000 & 81 & 22,69 & 493.259 & 1,16 \\
De 10.001 a 25.000 & 82 & 22,97 & 1.360 .127 & 3,20 \\
De 25.001 a 50.000 & 63 & 17,65 & 2.241 .203 & 5,27 \\
De 50.001 a 100.000 & 54 & 15,12 & 3.888 .497 & 9,15 \\
De 100.001 a 250.000 & 37 & 10,36 & 5.443 .703 & 12,80 \\
De 250.001 a 500.000 & 22 & 6,16 & 7.574 .482 & 17,82 \\
De 500.001 a 1.000.000 & 12 & 3,36 & 7.712 .769 & 18,14 \\
+ de 1.000.001 & 6 & 1,68 & 13.790 .722 & 32,44 \\
TOTALES & 357 & 100,00 & 42.504 .762 & 100,00 \\
\hline
\end{tabular}

El cuadro nos deja ver, en primer lugar, la clara distinción entre los cuatro primeros grupos, entre I y 100.000 reales, en los cuales siempre el porcentaje de inventarios sobrepasa el porcentaje del activo acumulado; y los últimos cuatro sectores, entre 100.001 y más de 1.000 .000 de reales, donde ocurre todo lo contrario. El resultado es que los 280 inventarios con menos de 100.000 reales, el $78,43 \%$ del total, tan sólo registran 7.983 .086 reales, el 18,78\% del global de los activos. Mientras que 77 inventarios superiores a 100.000 reales, el $21,57 \%$ de todos ellos, acaparan 34.521 .676 reales, lo que significa un $81,12 \%$ de la totalidad del activo. Y podemos concretar más: un 45,66\% de los inventarios, los que no sobrepasan los 25.000 reales, tan sólo contienen un 4,36\% del activo; en tanto que un 5,04\% de los inventarios, los que tienen más de 500.001 reales, acumulan hasta el 50,58\% del activo global. Por ello, a la disparidad habría que añadir como elemento peculiar la extrema polarización de las fortunas, fiel reflejo de la sociedad imperante que mostramos páginas atrás ${ }^{25}$.

\footnotetext{
${ }^{25}$ La polarización en Jerez es aún más acusada que la señalada para Morón por SÁNCHEZ LORA, José Luis: Capital y conflictividad social..., p. 25, donde un 7,7\% de inventarios, con más de 200.000 reales, acaparaba un $48 \%$ del activo, mientras que un $59 \%$ de inventarios, con menos de 30.000 reales, llegaba a recoger el $9,9 \%$ de la totalidad del activo.
} 
Los activos reseñados resultan de la suma de diversas partidas. Una clasificación primaria de éstas nos la da, en bastantes ocasiones, la propia fuente documental. No obstante, conviene llevar a cabo un agrupamiento sistemático y razonado de dichas partidas, de tal forma que permita un mejor acercamiento y conocimiento de las personas y grupos sociales a los que se refieren los inventarios ${ }^{26}$. Por nuestra parte hemos realizado una división primaria entre bienes muebles e inmuebles, seguida de una subdivisión de estas dos partidas en ocho grandes bloques. Veamos, pues, los datos y la información resultante.

Los bienes muebles incluyen seis grupos: capital, confort, herramientasmercancías, productos agrícolas, ganado y pertrechos. Los inmuebles, por su parte, se dividen en dos grupos: edificios y tierras. En el cuadro 3 podemos ver la distribución del activo, en cantidades absolutas y porcentuales, entre las diferentes partidas nombradas, con alusión al número de inventarios en los que se detecta cada partida.

Lo primero que llama la atención es el mayor peso de los bienes muebles en relación a los inmuebles en el conjunto de los inventarios, $60,3 \%$ sobre $39,7 \%$. Esto se explicaría, en parte, por el fenómeno ya apuntado de la vinculación de casas y tierras. Las propiedades vinculadas, con una sucesión ya reglada, no precisan ser recogidas en unos inventarios que tienen como finalidad última el reparto de los bienes libres del difunto.

Cuadro 3. Partidas y sus activos (en reales) en los inventarios jerezanos.

\begin{tabular}{|l|c|c|c|c|}
\hline \multicolumn{1}{|c|}{ Partida } & $\begin{array}{c}\text { número de } \\
\text { inventarios }\end{array}$ & $\begin{array}{c}\text { \% sobre total } \\
\text { inventarios }\end{array}$ & $\begin{array}{c}\text { activo } \\
\text { acumulado }\end{array}$ & $\begin{array}{c}\% \text { sobre } \\
\text { total activos }\end{array}$ \\
\hline Capital & 202 & 56,58 & 8.367 .397 & 19,60 \\
Confort & 226 & 63,30 & 2.746 .933 & 6,45 \\
Herramientas-mercancías & 58 & 16,25 & 483.985 & 1,15 \\
Productos agrícolas & 164 & 45,94 & 7.338 .981 & 17,25 \\
Ganado & 151 & 42,30 & 5.635 .606 & 13,20 \\
Pertrechos & 154 & 43,14 & 1.136 .963 & 2,65 \\
Subtotal Mueble & - & - & 25.709 .865 & 60,30 \\
Edificios & 313 & 87,68 & 11.021 .156 & 25,85 \\
Tierras & 187 & 52,38 & 5.907 .248 & 13,85 \\
Subtotal Inmuebles & - & - & 16.928 .404 & 39,70 \\
\hline
\end{tabular}

${ }^{26}$ Sobre las distintas partidas de los inventarios véase, entre otros, ARANDA PÉREZ, Francisco J.: "Prosopografia...", pp. 270-273 y SÁNCHEZ LORA, José Luis: Capital y confilictividad social..., pp. 22-23. 
En cuanto a las distintas partidas comenzamos por la de capital, que asciende a una valoración de 8.367 .397 reales. Son 202 los inventarios que incluyen este tipo de bienes, por lo que el capital medio se sitúa en 41.423 reales. No obstante, hasta 160 inventarios, el 79,2\%, se encuentran por debajo de la media mencionada, mientras que sólo 2 inventarios, el $1 \%$, acaparan el $49,1 \%$ de la totalidad de este asiento. En relación con esto, hay que indicar que es precisamente en esta partida en la que más se nota la distorsión generada por ẹl inventario extremo de D. Teodoro José de Roy, ya que de los 8.367 .397 reales del conjunto, hasta 3.218.978 son suyos. El bloque de capital se conforma, a su vez, por las subpartidas que relacionamos a continuación. Deudas a favor, aquellas cantidades que diversas personas adeudaban al difunto, que con 4.277.907, un 51,1\%, aparece en lugar preferente. Son 139 los inventarios que recogen deudas a favor, lo que nos indica como, ante la falta de un sistema bancario, se recurre muy a menudo a los préstamos interpersonales. En dinero efectivo hemos contabilizado 2.011,447 reales, un $24 \%$ del global de la partida de capital. Al parecer, las pequeñas cantidades de dinero que tuvieran los difuntos no suelen aparecer en la documentación, ya que sólo 97 inventarios hacen alusión a esta subpartida, aunque con una media ciertamente destacable, 20.700 reales. En acciones o participaciones en empresas hay 1.531 .003 reales, un $18,3 \%$, ahora bien, sólo se localizan en cuatro inventarios, y uno de ellos, el del sr. Roy, acapara 1.237 .500 reales. Hasta 13 inventarios hacen referencia a censos hipotecarios, subpartida que, por tratarse de un bien generalmente vinculado, no abunda más. Los censos tienen un valor de 307.654 reales, el 3,7\% de la partida de capital. Hay 49 inventarios que incluyen ingresos, percibidos o por percibir, de diversas rentas (arrendamicntos de casas y tierras, pensiones, réditos, etc.), por un total de 163.898 reales, un $2 \%$ del global del bloque. Para terminar, tenemos 10 inventarios que recogen la posesión de algunos oficios, valorados en 69.113 reales, un $0,8 \%$, y un solo documento que incluye juros evaluados en 6.375 reales, el $0,1 \%$ de la totalidad del capital.

La partida de confort alcanza los 2.746 .933 reales, distribuidos entre 226 inventarios, por lo que tenemos una media de 12.155 reales. Indicar que 179 inventarios, el $79,2 \%$, se encuentran por debajo de dicha media, mientras que 47 , el $20,8 \%$, la superan. Concretando más, podemos decir que 94 inventarios, un $42 \%$, no superan por este concepto, individualmente, los 2.000 reales, situándose en el otro extremo cuatro jnventarios, el $1,77 \%$, cada uno con más de 100.000 reales, que acumulan el $36 \%$ de la valoración global de la partida. Dentro del confort hemos incluido las siguientes subpartidas. En prinier lugar los enseres domésticos (muebles, menaje, cuadros, lamparas, cobre y peltre, vidrios, etc.), que con 907.220 reales alcanzan el 33\% de la partida. Son 212 los inventarios que recogen enseres domésticos, por lo que la media sólo llega a 4.279 reales, lo que incide en la frugalidad del mobiliario de la mayor parte de los domicilios. La plata 
labrada aparece en 134 inventarios, estando evaluada en 700.920 reales, un $25,5 \%$ del total de la partida. A ello habría que añadir los 388.989 reales, un $14,2 \%$, en los que están valoradas las joyas relacionadas en 86 inventarios. Dichas dos subpartidas conformarían el posible atesoramiento $y$, a la vez, las reservas de las familias para momentos de dificultad económica. La ropa, personal o de la casa, es un elemento que muchas veces escapa a los inventarios, ya sea por considerarse lecho cotidiano, por su escaso valor o, en casos de enfermedad, por procederse a su destrucción. Son 150 los inventarios que hacen alusión a las ropas, que alcanzan un valor de 435.001 reales, el $15,8 \%$ de la partida de confort. Un signo de alta posición social lo constituye la posesión de carruajes. En 13 inventarios aparecen estos medios de locomoción, apreciados en 180.552 reales, un 6,6\%. Menores aportaciones se deben a los oratorios recogidos en 8 inventarios con 99.230 reales, un 3,6\%. A los libros reseñados en 20 inventarios, valorados en 22.632 reales, un $0,8 \%$. Y a diversos tipos de armas (puñales, dagas, escopetas, pistolas) que encontramos hasta en 41 inventarios, todas ellas apreciadas en 12.379 reales, un $0,5 \%$ de la partida de confort.

La partida de herramientas-mercancías, con sus 483.985 reales, es la que presenta una menor cuantía de todas las que vamos a analizar. Se distribuye entre 58 inventarios, lo que implica una media de 8.345 reales. Dicha media no es alcanzada por 43 inventarios, el $74,14 \%$, mientras que 15 , un $25,86 \%$, sobrepasan dichos 8.345 reales. Indicar que 17 inventarios, un $29,3 \%$, no superan individualmente los 2.000 reales, cuando los 3 mayores, un 5,17\%, con más de 25.000 reales cada uno, acaparan el 39,66 de la totalidad de la partida. La subdivisión, en este caso, sólo recoge dos elementos. Por una parte, las herramientas de taller que encontramos en 40 inventarios, valoradas en 74.849 reales, el $15,46 \%$, por lo que la media es ínfima, 1.871 reales. Y, por otra, las mercancías o géneros no agrícolas, que alcanzan los 409.136 reales, el $84,54 \%$, y que se distribuyen entre 36 inventarios.

Las últimas tres partidas muebles que procedemos a analizar están intimamente relacionadas, pues todas hacen alusión a la actividad agrícola-ganadera. Empezamos por la partida de productos agrarios, compuesta por las existencias de lo producido por los distintos cultivos $y$, en algunos casos, por excedentes adquiridos para su posterior comercialización. El montante de esta partida asciende a 7.338 .981 reales, que se reparten entre 164 inventarios, con el resultado de 44.750 reales de promedio. Hasta 130 particiones, el $79,27 \%$, se sitúan por debajo de la media, mientras que 33 , el 20,73\%, la sobrepasan. Señalar que son 27 , un $16,5 \%$, los inventarios que no superan los 2.000 reales, cuando los seis mayores, un 3,7\%, con más de 250.000 reales cada uno, acumulan el $43,75 \%$ del total de la partida de productos agrarios. A efectos de simplificar hemos reagrupado los 
elementos de este bloque en siete subpartidas. La primera estaría constituida por las existencias del cereal más cultivado en el término, el trigo, valoradas en 2.903 .986 reales, el 39,56\% del total de los productos agrarios, que se distribuye entre 99 inventarios. Le sigue en importancia los productos de la vid, ya sea la uva o sus derivados (vino, vinagre y aguardiente), con 2.259.024 reales, el $30,78 \%$, de los cuales 2.002 .623 corresponde al valor de los vinos almacenados. El númeto de inventarios que incluye esta subpartida es de 97. A cierta distancia encontramos en 44 inventarios los barbechos o sembrados no recolectados, que se evalúan en 852.542 reales, el $11,61 \%$ del grupo de productos agrarios. Otros granos y legumbres (cebada, arvejón, habas, garbanzos y sahína) conforman la cuarta subpartida, alcanzando un monto de 669.856 reales, el $9,13 \%$, que se reparten entre 67 inventarios. Las existencias de paja, ligadas al cultivo de los cereales y a la alimentación animal, son muy destacables, estando apreciadas en 327.160 reales, un $4,46 \%$, y las podemos localizar hasta en 57 documentos. Las aceitunas y el aceite, en proporción de 1 a 4 , encontradas en 39 inventarios, tienen un valor de 264.954 reales, el $3,61 \%$ de todo el montante de productos agrarios. Por último, otros productos diversos, que aparecen en 49 inventarios, siempre en mínimas cantidades, se evalúan en 61.152 reales, lo que significa un $0,84 \%$ del total de la partida.

Son 151 los inventarios que recogen la presencia de algún tipo de ganado. El número de cabezas asciende a 39.611 , alcanzando un valor de 5.635 .606 reales, por tanto, 37.321 reales de media por inventario. Ahora bien, 119 documentos, el $78,8 \%$, se encuentran por debajo de dicho promedio, mientras que los restantes 32 , un $21,2 \%$, lo superan. La polarización es notable, ya que, individualmente, hay 71 inventarios, un $47 \%$, con menos de 2.000 reales en ganado, cuando 6 inventarios, el $4 \%$, con más de 250.000 reales, acumulan el $45,9 \%$ del valor de toda la cabaña ganadera computada. En base al tipo de ganado hemos dividido este bloque en 9 subpartidas. En primer lugar destacan las 7.344 cabezas de ganado vacuno localizadas en 71 inventarios, las cuales están evaluadas en 2.817 .831 reales, el $49,8 \%$ del total de la partida. Indicar que de entre todos los vacunos podemos concretar la presencia de hasta 2.176 bueyes de arada o de carreta, elementos indispensable para las labores agrícolas. Sigue al vacuno, ya a cierta distancia, las 2.569 yeguas, caballos y potros, con un valor de 1.553 .147 reales, un $27,4 \%$, que se distribuyen entre 97 inventarios. El tercer lugar lo ocupan las 22.361 cabezas de ganado ovino, que, repartidas en sólo 22 inventarios, tienen un aprecio de 438.961 reales, el $7,8 \%$ de la totalidad de la partida. Los asnos y jumentos, 1650 cabezas, alcanzan un evalúo de 287.973 reales, un 5,1\%, siendo los animales que aparecen en un número mayor de documentos, hasta en 101 . Un valor de 278.538 reales, el $4,9 \%$, es el que tienen los 3.314 cerdos contabilizados en 27 inventarios. El ganado mular es escaso, 186 cabezas, pero tiene un altr 
aprecio, por lo que llega a los 164.552 reales, un $2,9 \%$, siendo el número de propietarios de 40 . Al contrario, el ganado caprino alcanza las 2.187 cabezas, pero su valor no supera los 61.012 reales, un $1,1 \%$, siendo su distribución entre tan sólo 4 inventarios. Por último, tenemos dos subpartidas menores, que se corresponden a las colmenas contabilizadas en 38 inventarios, con 32.629 reales, un $0,6 \%$, y a las aves de corral enumeradas en 24 particiones, con 22.373 reales, un mínimo $0,4 \%$ del total de la partida de ganadería.

Relacionada con las dos partidas precedentes estaría la de los pertrechos, donde se recogen, como luego veremos, tanto los aperos de campo, como los precisos para la transformación de la uva en mosto y los necesarios para el almacenaje de éste y de los vinos. Son 154 los inventarios que presentan algún tipo de pertrechos de los mencionados, todos ellos valorados en 1.136 .963 reales, por lo que el promedio, escaso, es de 7.383 reales. Por debajo de dicha media se encuentran 117 inventarios, un $76 \%$, mientras que 37, un $24 \%$, la rebasan. Puntualizar que son 71 inventatios, un $46,1 \%$, los que no llegan a superar, individualmente, los 2.000 reales, hallándose 9 , un $4,54 \%$, con cantidades superiores a los 25.000 reales cada uno, que concentran el $38,2 \%$ del valor total de los pertrechos. Este bloque lo hemos dividido en cuatro subpartidas. La primera corresponde a los pertrechos de bodega, principalmente recipientes para el almacenaje de los vinos, que se evalúa en 754.796 reales, un $66,4 \%$, distribuidos entre 104 inventarios. Señalar que dentro de esta subpartida las botas, por sí solas, tienen un aprecio de 575.681 reales. La segunda subpartida la constituyen los aperos de labranza que encontramos en 71 inventarios, con un aprecio de 341.966 reales, un $30 \%$ del total de pertrechos. Entre los aperos destacan las carretas, 267 valoradas en 63.826 reales. Las dos últimas subpartidas son minoritarias, una recoge el evalúo de los lagares contabilizados en 76 documentos, 35.810 reales, un $3,2 \%$, mientras que la otra el valor de los aperos utilizados exclusivamente para la labranza de las viñas que detectamos en 32 inventarios, con 4.700 reales, un $0,4 \%$ del total de pertrechos.

Como ya anunciamos, los bienes inmuebles se agrupan en dos grandes bloques: los edificios y la tierra. Reseñar que los aprecios que vamos a dar aquí de ambos son los valores líquidos, descontados los montantes de los censos hipotecarios que pesaban sobre ellos, ya que nos interesa sobretodo conocer la liquidez, el capital libre, de los inventarios. Los edificios alcanzan una cuantía de 11.021.156 reales, siendo el bien más universal, ya que aparece en 313 inventarios, siendo el promedio de 35.211 reales. Como siempre, las medias no son fiel reflejo de la realidad. Asi, 239 inventarios, un 76,36\% se sitúan por debajo del promedio, mientras que 74 , un $23,64 \%$, lo superan. Ahora bien, la polarización no es en esta partida tan acusada, ya que sólo 15 inventarios, un 4,8\%, no llegan 
a sobrepasar los 2.000 reales, siendo 5 , un $1,59 \%$, los que tienen edificios valorados en más de 250.000 reales, acumulando entre ellos sólo el 19,33\% de la partida. Hemos distinguido tres tipos de edificios. En primer lugar las viviendas urbanas, valoradas en bruto en 10.591 .562 reales y descontados los censos (que alcanzan un porcentaje del $20,08 \%$ ) en 8.464 .855 reales, un $77,65 \%$ del valor de todos los edificios. Son 293 los inventarios que recogen estas viviendas urbanas. Hasta 46 documentos hacen referencia a las bodegas, instalación industrial fundamental en una ciudad vitivinícola como Jerez. El aprecio de estas bodegas es, en bruto, de 1.547.228 reales, y líquido, sin censos (con un porcentaje del 12,3\%), de 1.356 .845 reales, el $12,45 \%$ de la partida. Por último, las instalaciones del campo, precisas para la labor o la ganadería, nunca hipotecadas por su escaso valor, son apreciadas en 1.080 .601 reales, un $9,9 \%$. Se localizan estos edificios rurales en 124 inventarios.

Para finalizar sólo nos resta la partida correspondiente a la tierra. Su relativa significación no se corresponde con la amplitud del término jerezano ni con la importancia de la actividad agrícola de la localidad, y ello debido al fenómeno, ya varias veces apuntado, de la vinculación, que hace que las propiedades rústicas, mayoritariamente, no se recojan en las particiones. Es más, la imagen que ofrece la propiedad de la tierra en los inventarios, pequeñas parcelas dedicadas, generalmente, al cultivo de la vid, no refleja la verdadera estructura rural de Jerez de la Frontera. Son 187 inventarios los que recogen un total de 4.511 aranzadas de tierras, valoradas en 5.907.248 reales líquidos. La media estaría, por tanto, en los 31.590 reales. Cantidad que no alcanzan 137 inventarios, el 73,26\%, mientras que los otros 50 , un $26,74 \%$, la sobrepasan. Al igual que ocurría con los edificios, aqui la polarización extrema no es tan acusada. Sólo 5 documentos, un 2,67\%, no llegan a superar los 2.000 reales, siendo 2 , un $1,07 \%$, los que tienen más de 250.000 reales, acaparando el 10,35\% de la partida de tierras. En base al tipo de cultivo hemos establecido cinco subpartidas. La más destacada corresponde a 2.300 aranzadas de viña, valoradas en bruto en 5.009 .370 reales, $y$ en líquido, descontados los censos (con un porcentaje del 22\%), en 3.904 .948 reales, el $66,35 \%$ del total del valor de las tierras. La viña aparece en 147 inventarios. Le sigue la subpartida dedicada a la tierra calma o de cereal, que recogemos en 70 inventarios. El número de aranzadas es de 1.469 que están apreciadas en 1.241.295 reales incluidos los censos y sin éstos (con un porcentaje del 30,5\%) en 861.910 reales, un $14,65 \%$ de la partida. Las 499 aranzadas de olivar contabilizadas en 38 inventarios constituyen la tercera subpartida. Fueron evaluadas, incluidos los valores de los censos, en 1.081 .980 reales y, descontados éstos (con un porcentaje del $25,6 \%$ ) en 804.624 reales, el $13,67 \%$. De huerta y árboles frutales encontramos 79 aranzadas en 12 documentos. Son las tierras mejor apreciadas, alcanzando un valor en bruto de 213.835 reales y sin censos (con un porcen- 
taje del $19,7 \%$ ) de 171.617 reales, el 2,91\%. Por último, tenemos en 12 inventarios hasta 164 aranzadas de tierra de las que no se especifica su aprovechamiento. Su evalúo era de 202.353 reales en bruto y en líquido, sin censos (con un porcentaje del $29,7 \%$ ), de 142.339 reales, un $2,42 \%$ del total de la partida de tierras.

Hasta aquí, el estudio global de los capitales inventariados, del cual podemos obtener las siguientes conclusiones.

El predominio de los bienes muebles sobre los inmuebles. Cuestión relacionada con la fuerte incidencia de la vinculación en las propiedades urbanas y rústicas.

En las ocho grandes partidas analizadas se observa una cierta similitud en cuanto a los porcentajes de inventarios que se sitúan por debajo y por encima del promedio de la correspondiente partida. Asfi, el porcentaje de los que no alcanzan la media fluctúa, según los casos, entre el 73 y el $79 \%$, mientras que los que la superan se sitúan entre el 21 y el $27 \%$. Es decir, en todas las partidas por cada tres inventarios por debajo de la media hay uno que la supera.

Por otra parte, el fenómeno de la acumulación en pocos inventarios es patente en todas las partidas a excepción de la correspondiente a los edificios inmuebles, en la que la polarización no es tan extrema. Salvando este caso, en las demás partidas entre el 1 y el $4 \%$ de 10 inventarios acapara entre el 30 y el $50 \%$ del global de cada bloque.

Aunque la partida de capital está algo distorsionada por la incidencia del inventario excepcional del sr. Roy, no por ello deja de llamar la atención su significación en el conjunto de los elementos constituyentes de las fortunas. Siendo especial el papel de las deudas a favor, tanto por el número de inventarios en el que aparecen, 139 , un $39 \%$ de la totalidad, como por su cuantía, 4.277 .907 reales. Si a ello añadimos otro dato, el de las deudas en contra, que se localizan en 203 inventarios, un $57 \%$, con un montante de 5.043 .422 reales, nos podemos hacer una diáfana idea de la generalidad y funcionalidad de los préstamos interpersonales. Y ello, de forma peculiar en localidades con predominio de la actividad agrícola, como Jerez, en las que el ciclo regular de labranza y cosecha, obliga a muchos a recurrir al préstamo mientras no se procede a la recolección y venta de la producción.

La partida de confort no tiene una gran presencia, más bien nos encontramos con parcos mobiliarios, ropas sencillas y escasos elementos suntuarios. Tan sólo destaca la plata labrada, localizada en 134 inventarios, aunque puede tener, en muchos casos, una función más de reserva económica que de ostentación. 
Las partidas de productos agrícolas, ganado, pertrechos y herramienta-mercancías nos corroboran fielmente la estructura económica de la ciudad presentada en el apartado anterior de este artículo, con un predominio total de las actividades agrícola-ganaderas sobre las demás.

Aunque la partida respectiva a las tierras nos describa un agro donde parece destacarse el cultivo de la vid, aprovechamiento no sometido tanto a la vinculación como las tierras de cereal u olivar, lo cierto, y así se puede comprobar tras el análisis de la partida de productos agrícolas, es que son las tierras de pan sembrar, con los granos (trigo y cebada) y otras semillas, junto con su paja y sus barbechos, las que verdaderamente predominan. Estos productos constituyen hasta el $65,6 \%$ de la partida, frente al $30,8 \%$ de la uva y el vino y el escaso $3,6 \%$ del aceite.

En consonancia con las labores que precisan los granos, tenemos una ganadería en la que destacan, especialmente, el ganado vacuno (bueyes de arada y de transporte) y el equino (yeguas para la trilla). Ganado que, junto al asnal, se encuentra bastante extendido entre múltiples propietarios, mientras que llama la atención la concentración en pocos inventarios del ganado lanar, caprino y porcino.

Por último, tal como ya habían adelantado anteriores investigaciones, se observa la existencia de un utillaje agrícola escaso, pobre y relativamente de escaso valor, que contrasta con el alto montante de inversión que precisan los pertrechos destinados al almacenaje de los mostos y vinos ${ }^{27}$.

\section{Análisis socio-profestional de los activos}

En las páginas de la introducción planteábamos que el objetivo de este trabajo no consistía tan sólo en desmenuzar la estructura interna de las fortunas jerezanas, sino que nuestro interés radicaba en obtener, mediante el análisis de las mismas, un mejor conocimiento de la sociedad de Jerez y de las pautas de comportamiento de sus distintos elementos.

Sabemos que dichos fines, trabajando con una fuente documental como los inventarios post-mortem, de los que ya hemos argumentado sobre algunas de sus limitaciones, no pueden ser alcanzados en su totalidad. $Y$ es que algunos grupos sociales escapan, por diversos motivos, al estudio. Así, nuestra aportación será

"Ver el artículo de ÁLVAREZ SANTALÓ, L.C. y GARCÍA-BAQUERO, A.: "El utillaje agricola en la tierra de Sevilla, 1700-1833", en Archivo Hispalense, 193-194 (1981), pp. 235-267, en concreto las pp. 249 y 254. 
nula sobre la población que no posee bienes algunos, o éstos son tan exiguos que su valor no requiere la formalización de un inventario. Todos conocemos la amplitud de este sector poblacional indigente o en el umbral de la pobreza que, generalmente, no deja huella en la documentación notaria ${ }^{28}$, y que, en el caso de Jerez, casi con toda seguridad, oscilaría entre el 60 y el $80 \%$ del vecindario. Por otra y contraria parte, tenemos el grupo constituido por las tradicionales familias potentadas de la localidad, que se sustentan económicamente gracias a las rentas que les proporcionan sus fuertes patrimonios vinculados ${ }^{29}$. La inexistencia de bienes libres o la parquedad de los mismos, tiene como consecuencia que estos vecinos poderosos, generalmente miembros de la nobleza, se vean, pocas veces, inmersos en procesos de partición.

Excluidos, mayoritariamente, los miembros de estos dos sectores sociales extremos, los inventarios nos van a acercar, preferentemente, a los grupos medios de la socicdad jerezana, lo cual no deja de ser relevante, ya que éstos son los elementos más dinámicos del conjunto social y los más representativos para un estudio de la reproducción del sistema y de los cambios que el mismo pueda experimentar. Los 357 inventarios se han distribuido entre 10 grupos socioeconómicos. La adscripción a uno $\mathrm{u}$ otro no ha resultado fácil. Tan sólo en 105 casos se hacía mención, expresamente, a la profesión o actividad ejercida por el finado o por su cónyuge, si la fallecida era mujer. De los 252 restantes, hasta 162 han podido ser ubicados en algún grupo en base al análisis de las partidas que componían el inventario o a la información indirecta reseñada por la documentación. Los otros 90 no aportaban dato alguno que permitiera su clasificación, por lo que componen, por sí solos, uno de los grupos sociales, el que hemos denominado de ocupación indeterminada. Indicar, que hay vatios casos que se podrían haber ubicado, indistintamente, en una u otra categoria, optando siempre por la más relacionada con la actividad que parecía prevalecer según las partidas de la fortuna ${ }^{30}$.

Los 10 grupos o categorías socioeconómicas son los siguientes. A) Los labradores, que serían aquellos individuos que se dedican, preferentemente, a las labores agrícolas, cultivando una extensión amplia de tierras, propias o arrendadas, y contando con más que suficientes medios de producción (ganado y aperos). B) Los viticultores, exclusivamente pequeños y medianos cultivadores de parce-

\footnotetext{
${ }^{28}$ Diversos autores han constatado que los grupos socioeconómicos más relevantes tienen una mayor presencia en las fuentes documentales, y especiaimente en las de protocolos. Entre otros, ARANDA PÉREZ, Francisco J.: "Prosopografia...", p. 262.

${ }^{2}$ Así, por ejemplo, los regidores de Jerez, Jos caballeros veinticuatros, tenian vinculadas el $98,65 \%$ de sus propiedades agricolas y el $76 \%$ de los inmuebles urbanos. Sobre ello, GONZÁLEZ BELTRÁN, I.M.: Honor, riqueza y poder..., pp. 67-69.

"La cuestión de la clasificación en categorias ya planteada por ÁLVAREZ SANTALÓ, L.C. y GARCÍA-BAQUERO, A.: "Funcionalidad del capital...", p. 107. En su trabajo los indeterminados alcanzan un porcentaje del $23,44 \%$, casi idéntico al $25,22 \%$ que nosotros manejamos.
} 
las de viñedo. C) Los vitivinicultores serían personas que, además de al cultivo de la vid, se dedicaban a la elaboración y venta de mostos y vinos. D) La gente del campo, grupo constituido, a excepción de los individuos que entran en las tres categorias anteriores, por todos aquellos que se dedican a las labores agrícolas, bien como pequeños propietarios o arrendatarios de tierras, preferentemente de cereal, o como trabajadores. E) El grupo con menos problemas de clasificación es el correspondiente a los artesanos o personas ocupadas en el sector secundario de la economía. F) La categoría de los individuos del comercio comprende un heterogéneo grupo donde, junto a grandes comerciantes como el sr. Roy, encontramos dueños de diversas tiendas dedicadas a la alimentación y mercaderes con cierta especialización. G) Aunque podrian ir en la misma categoria que los comerciantes, ciertas peculiaridades aconsejan constituir un grupo concreto con el pequeño número de personas que se dedican al transporte como actividad. $\mathrm{H}$ ) También una categoria heterogénea es la que hemos denominado como de profesionales, en la que se incorporan, juntos a los propios profesionales liberales, el personal de las administraciones, incluidos eclesiásticos. I) Los hacendados conforman una categoría más social que económica, ya que no se deduce que realicen actividad lucrativa alguna, pero si se detecta su alta estima social y la percepción de rentas del patrimonio. J) Por último, los indeterminados, grupo con individuos de escasas fortunas y con presencia mayoritaria de nujeres viudas 0 solteras. Procederemos, en primer lugar, a un análisis global del conjunto según los inventarios para, posteriormente, concretar aspectos de cada una de las categorías sociales arriba mencionadas.

En el análisis global nos ayudaremos de los cuadros 4 y 5 , en los cuales se recogen, en base a los ocho niveles posibles de activos, la distribución de los inventarios entre las diez categorías socioprofesionales, así como los activos que cada una de dichas categorías acumulaba. En la visión general, para huir del deta1 lismo excesivo, tendremos en cuenta dos aspectos. Primero, una división entre los que superan o no los 100.000 reales de activo total, cantidad que consideramos, con todas las reservas posibles, la que puede servir de límite entre la simple posesión y las posibilidades de acumulación ${ }^{31}$. Mencionar, como ya se expuso, que el $78,43 \%$ de los inventarios no alcanzaban los 100.000 reales, mientras que el $21,57 \%$ los sobrepasaban. $Y$, segundo, la polarización extrema, tanto la inferior, la de aquellos que no exceden de los 25.000 reales, como la superior, la de los que

\footnotetext{
"Álvarez SANTALó, L.C. y GARCÍA-BAQUERO, A.: "Funcionalidad del capital...", p. 110, plantean como nivel indicativo de fortuna el superar los 250.000 reales. Pero ellos trabajan con inventarios, mayoritarianente, del siglo XIX y referidos a una gran capital. Por otra parte, SÁNCHEZ LORA, José Luis: Capital y conflictividad social..., pp. 53-61, aunque no lo diga expresamente, parece decantarse por los 100.000 reales.
} 
superan los 500.000 reales. Recordar que en la primera situación se encontraban el $45,66 \%$ de los inventarios y, en la segunda, tan sólo el 5,04\%.

Hay siete grupos socioprofesionales en los que, mayoritariamente, los inventarios presentan activos inferiores a los 100.000 reales. Asi., los indeterminados y los transportistas, con hasta el $100 \%$ de los casos; la gente del campo, con un $98,46 \%$; los artesanos, con el 94,73\%; los viticultores, con el $88,90 \%$; los profesionales liberales, con un significativo $80,95 \%$; e, incluso, los comerciantes, aunque su $65,51 \%$ se encuentra ya por debajo de la media general. Por otra parte, con activos generalmente por encima de los 100.000 reales encontramos a los labradores, en el 71,10\% de los casos; a los vitivinicultores, con el 66,60\%; y, en menor medida, a los hacendados, con el 55,56\%. Indicar que los comerciantes, aún no siendo mayoritarios en este bloque, presentan un porcentaje, el 34,49\%, superior al que registra la media general. En cuanto a la polarización extrema, destacar que con menos de 25.000 reales tenemos el $86,66 \%$ de los indeterminados y el $66,15 \%$ de la gente del campo. Mientras que, por encima de los 500.000 reales, aparecen los labradores, en el $30,95 \%$ de sus casos; los hacendados con el $11,11 \%$; y, en menor proporción, los comerciante, con el 6,89\%. La moda, por su parte, inciden en el panorama ya presentado. Entre 1 y 10.000 reales es el nivel en el que más inventarios de indeterminados encontramos. La gente del campo se halla en el nivel de 10.001 a 25.000 . Los viticultores, artesanos y transportistas presentan una mayor presencia en el nivel de 25.001 a 50.000 reales. Los profesionales liberales en el de 50.001 a 100.000. En el siguiente nivel de activos, de los 100.001 a 250.000 reales se localizan el mayor número de inventarios de los vitivinicultores, comerciantes y hacendados. Por último, los labradores sitúan su moda en el nivel de los 250.001 a 500.000 reales.

Hasta ahora se ha visto específicamente la distribución del número de inventarios, la cual, la completaremos, con la distribución de los activos entre las diversas categorías socioprofesionales. Conviene recordar que el $81,12 \%$ de los actiyos se acumulaba en los inventarios de más de 100.000 reales, y el 18,78\% restantes en los que no alcanzaban dicha cantidad. Del mismo modo, que los inventarios de más de 500.000 reales concentraban el 50,58\% de los activos, mientras que los que no sobrepasaban los 25.000 reales tan sólo reunían el 4,36\% del total de los activos. Pues bien, son 5 los grupos socioprofesionales en los que sus activos se concentran en los inventarios de menos de 100.000 reales. Así ocurre con los indeterminados y los transportistas, lo cual no podía ser de otra manera ya que el $100 \%$ de los inventarios de estas categorías presentan menos de 100.000 reales. La gente del campo acumula en este bloque el $91,37 \%$ de sus activos, los artesanos el $83 \%$ y, por último, los viticultores el $61,13 \%$. Por otro lado, concentrando sus activos en los inventarios con más de 100.000 reales, encontramos a las 
restantes 5 categorías. Sobresalen los labradores con el $96,17 \%$ del total de sus activos. Le siguen, a corta distancia, los comerciantes, los vitivinicultores y los hacendados, con el $90,4 \%$, el $90,03 \%$ y el $89,48 \%$ respectivamente. $Y$, algo más descolgados, los profesionales liberales con el $51,11 \%$. En cuanto a la polarización extrema indicar que son los indeterminados los únicos que concentran mayoritariamente sus activos en los niveles de menos de 25.000 reales, con un $58,16 \%$. Mientras que en los niveles superiores a los 500.000 reales se acumula el 77,45\% de los activos de los comerciantes (aunque en este caso habría que tener en cuenta la distorsión producida por el sr. Roy), el $67,25 \%$ del de los labradores y el $45,74 \%$ del de los hacendados.

Del análisis general pasamos al de las distintas categorías socioprofesionales, el cual iniciamos con los labradores. E1 número de inventarios que integran este grupo es de 42 , el $11,76 \%$ de la totalidad. Pero su significación les viene, sobre todo, por el montante de los activos que manejan, que alcanza los 19.545.548 reales, el $45,98 \%$ del total inventariado para todas las categorías. La media de los activos por labrador se sitúa en los 465.370 reales, promedio no igualado, ni de lejos, por ningún otro grupo social. En el conjunto de los niveles de activos, el $52,38 \%$ de los labradores se localiza entre Ios 250.001 y 1.000 .000 de reales. Pero, ¿cómo se distribuyen dichos activos entre las diferentes partidas de bienes?. Para contestar a esta pregunta nos valemos del gráfico 1.

Lo primero que llama la atención es el predominio de los bienes muebles, un $72,84 \%$, frente a los inmuebles, el 27,16\%. Esta desproporción viene determinada, sobre todo, por las aportaciones de las partidas de productos agrícolas, $26,06 \%$, y ganado, $26,88 \%$. Con respecto a la primera reseñar que, independientemente de la fecha en la que ocurre el fallecimiento, se suele esperar a la recolección de la cosecha para proceder al inventario, muestra de la importancia que se le otorgaba a esta partida. Excepto un inventario todos los demás presentan alguna cantidad de productos agrarios, siendo el promedio de su valor de 121.292 reales. En general, el $69,42 \%$ de la cuantía total de los productos agrícolas se encuentra en manos de los labradores. Por otra parte, el ganado se recoge en la totalidad de los casos, siendo la media de su evalúo de 125.079 reales. Y lo que es más significativo, los labradores acumulan el $93,22 \%$ del valor de toda la cabaña ganadera localizada en el estudio. En cuanto al tercer elemento relacionado con la labranza, los pertrechos, sólo dejan de detectarse en dos casos. Su incidencia en las fortunas de los labradores es escasa, un 2,75\%, aunque estamos hablando de una cantidad nada desdeñable de 12.809 reales de promedio. Además, los labradores concentran el 47,33\% del valor de todos los pertrechos. Los bienes muebles se complementan con un $11,75 \%$ de capital y un $5,40 \%$ en confort, partidas en las que localizamos a más de las tres cuartas partes de los 
labradores. La presencia de dinero en efectivo o deudas a favor es muy significativa en sus inventarios, siendo la media de 56.624 reales, y acumulando hasta el $27,42 \%$ del total de la partida de capital. Y en cuanto al confort, se refleja un buen status de vida, ya que presentan una media de 25.137 reales, el doble del promedio general de todos los inventarios, y reúnen el 38,43\% del montante total de este sector de las fortunas.

Sobre la escasa incidencia de los bienes inmuebles comentar que, a excepción de uno, todos poseen edificios, viviendas, las que representan un 17,36\% de sus activos, siendo el promedio de su valor de 80.811 reales y alcanzando el $30,8 \%$ del montante de la totalidad de esta partida. Pero resulta extraño, tratándose de labradores, la escasa importancia de las propiedades rústicas, con un $9,8 \%$ y un valor promedio de 45.618 reales, en el conjunto de sus bienes. Es más, sólo dos tercios del grupo aparecen como titulares de tierras. Ello nos está mostrando una categoría de labradores que basan su actividad en el arrendamiento de las grandes fincas que poseen los potentados locales. Ahora bien, a pesar de todo, acumulan el $32,43 \%$ de la cuantía total de esta partida.

La significación cualitativa del cultivo de la vid en Jerez nos va a proporcionar dos especiales categorías socioprofesionales: los viticultores y los vitivinicultores. Los primeros, pequeños y medianos propietarios y cultivadores de vides, los hemos localizados en 45 inventarios, el $12,6 \%$ de la totalidad. Sus activos no son muy considerables, 2.414 .872 reales, un mínimo $5,68 \%$ del montante general contabilizado en los inventarios. La media de las fortunas de los viticultores es de 53.664 reales, localizándose la mayoría de sus componentes en los niveles de 10.000 a 50.000 reales. La distribución de sus activos puede verse en el gráfico 2 .

Los viticultores presentan un predominio de bienes inmuebles, con un $75,5 \%$, frente a los muebles, con un $24,5 \%$. La importancia del patrimonio inmueble se debe a que todos poseen alguna propiedad nústica, lo que hace que la partida de tierras constituya el $48,41 \%$ de todos sus activos, y, lo que es más significativo, acumulen el $19,79 \%$ del valor global de esta partida, siendo sólo superados en ella por los labradores. El promedio del valor de las tierras es de 25.979 reales. A ello debemos sumar la fuerte presencia de edificios, que aporta el $27,09 \%$ de la fortuna, con una media de 14.540 reales por inventario, aunque en este caso la incidencia sobre el conjunto es menor, ya que sólo alcanzan el 5,93\% de la partida. Resulta interesante la actitud de este grupo socioeconómico, que invierte sus posibles ganancias en asegurar e incrementar su propiedad de viña y en hacerse con una vivienda propia.

En cuanto a los bienes muebles podemos decir que, en general, no sobresale esta categoría, ni por el número de individuos ni por las cuantías manejadas, en 
ninguna de las partidas. Poseen un pequeño capital, 3.915 reales de media; el producto de la cosecha de uva, con un valor medio de 3.948 reales; escasas comodidades, con 3.032 reales de promedio en confort; $y$ unos pertrechos reducidos, con 1.737 reales de media. El cultivo de la vid no precisa ni bueyes ni yeguas, por to que la presencia de ganado en prácticamente nula, 318 reales de promedio.

Esta visión cambia algo cuando hablamos de los vitivinicultores, que al cultivo de la vid añaden, en bastantes casos, la transformación de la cosecha en vino y el almacenamiento de éste, y, alguna vez, su comercialización. El número de vitivinicultores localizados es de 21 , lo que representa el 5,88\% de todos los individuos. Pero como ocurría con los labradores su importancia como grupo radica en los activos que manejan. Así, acumulan el 9,62\% de todo lo inventariado, o lo que es lo mismo, 4.090 .695 reales. Se localizan, mayoritariamente, con un $61,9 \%$, en los niveles de 100.001 a 500.000 reales. La media de sus fortunas asciende a 194.795 reales, cuya distribución podemos ver en el gráfico 3.

En este caso, los bienes inmuebles siguen aportando la mayor parte del activo, con un $63,31 \%$, quedando para los bienes muebles el $36,69 \%$ restante. La tierras no son, porcentualmente, con un $24,23 \%$, lo más destacado, aunque es un bien que posee la generalidad de la categoria, alcanzando una media de 47.210 reales, la más alta del conjunto social, incluso por encima de la de los labradores, y que constituye el $16,78 \%$ del total de esta partida. Recordar que las tierras de mayor valor son las de viñas, que son las que preferentemente posee este grupo. Si son los edificios, sobre todo por la aportación de las bodegas de almacenado, los que tienen una mayor incidencia, con el 39,08\% sobre el total de los activos del grupo y el $14,50 \%$ sobre la globalidad de los activos inventariados. El promedio por individuo alcanza los 76.122 reales.

El análisis de los bienes muebles nos descubre una categoría socioprofesional en la que en más de las tres cuartas partes de sus elementos adquiere una cierta relevancia el capital disponible, 25.035 reales de promedio; su relativo buen nivel de comodidad 9.773 reales de media en confort; el significativo valor de los nostos $y$ vinos, con 25.163 reales de promedio; y la necesidad de invertir en pertrechos de almacenado, que les lleva a tener, de media por esta partida, 7.659 reales.

El sector agrario se completa con 65 individuos, un $18,21 \%$ del conjunto, que denominamos, de forma genérica gente del campo. Se trata, mayoritariamente, de pequeños propietarios o arrendatarios de tierras dedicadas al cereal $y-0$ olivar. Su participación en los activos inventariados no es considerable, ya que con 1.746.579 reales sólo acumulan el 4,11\% del total. En el gráfico 4 podemos ver la distribución de sus fortunas, que alcanzan una media de 26.870 reales, la más baja de todos los grupos sociales a excepción de los indeterminados. 
Prevalecen los bienes inmuebles, con un 67,99\%, frente a los muebles, que presentan el $32,01 \%$ restante. Los edificios, con el 38,96\%, constituyen la partida sobresaliente de las propiedades inmuebles. Son más de las tres cuartas partes de los individuos los que poseen viviendas propias, alcanzándose una media de 10.657 reales. Las tierras, por su parte, aportan el $29,03 \%$ de las fortunas de las gentes del campo. En este caso sólo dos terceras partes poseen alguna porción de terreno, siendo el promedio de su valor de 7.943 reales, lo que equivale a entre 3 y 10 aranzadas.

En cuanto al conjunto de bienes muebles incidir, primero, en la escasa generalización de los mismos. Es decir, salvo en las partidas de productos agricolas y ganado donde se llega al $66 \%$, en las demás el número de los individuos contabilizados no alcanza la mitad de los 65 que conforman la categoría. Y, segundo, la mínima cuantía de los activos correspondientes a estas partidas. Así, los promedios de capital, confort y pertrechos quedan en $1.830,516$ y 469 reales respectivamente. Siendo algo más significativas las aportaciones al global de las fortunas tanto por productos agrarios, con una media de 4.024 reales, como por el ganado, con una media de 1.865 reales.

Los artesanos o, en general, los individuos con actividades manufactureras, son 19 , el $5,32 \%$ del total. Sus activos son escasos con un montante global de 710.485 reales, el $1,67 \%$ de todos los activos inventariados, siendo la media por persona de 37.394 reales. Los artesanos se ubican, en el $57,9 \%$ de los casos, en los niveles de entre 10.001 y 50.000 reales. En el gráfico 5 podemos apreciar la distribución de sus fortunas.

Destacan, una vez más, los bienes inmuebles, con el $59,11 \%$, frente a los muebles que llegan al $40,89 \%$. Son los edificios, las casas-taller poseídas por un $80 \%$ de los individuos de la categoría, las que aportan la mitad de los activos, un $51,22 \%$, siendo el promedio de su valor de 19.154 reales. La propiedad de tierras es mínima, el $7,89 \%$ del total del activo, proporcionando una media de 2.950 reales.

En cuanto a los bienes muebles señalar, como no podía ser de otra manera, la nula incidencia de las partidas correspondientes a ganado, productos y pertrechos agricolas. Pero se observa el aporte de las herramientas-mercancías, con un promedio de 2.756 reales; de los elementos de confort, cuya media es de 3.446 reales; y, especialmente, del capital, con 7.046 reales de promedio, que se debe sobre todo a las deudas de los clientes por trabajos realizados con pago aplazado.

El análisis de los comerciantes requiere una puntualización previa. Hemos optado por no contabilizar los datos relativos a D. Teodoro José de Roy, el único gran comerciante con el que contábamos. Y ello por dos razones. La primera por- 
que el sr. Roy, aunque fallece en Jerez, es oriundo de Cádiz y realiza su actividad mercantil desde dicha ciudad, por lo que responde más a la figura del comerciante tipo gaditano que a la del jerezano. Y segundo, porque su amplio caudal, cuantificado en el $60 \%$ del total acumulado por toda la gente del comercio, distorsionaba, enormemente, las características peculiares de esta categoría socioprofesional de Jerez. Por tanto, los individuos de la localidad relacionados con las distintas formas de comercio quedan en 28 , un $7,84 \%$ de todas las personas analizadas. Sus activos alcanzan un global de 3.337 .802 reales, un $7,85 \%$ del total inventariado, siendo el promedio de sus fortunas, cuya distribución vemos en el gráfico 6, de 119.207 reales. La mayoria de los componentes de este sector, el $46,4 \%$, se localizan en los niveles de activos de entre 50.001 y 250.000 reales.

La diferencia entre bienes inmuebles y muebles es, en este caso, mínima, resultando favorecidos los primeros, con un $50,36 \%$ sobre los segundos, que llegan al $49,64 \%$. Son los edificios los que presentan una mayor incidencia, con un $35,10 \%$, los poseen casi todos los miembros de la categoría, siendo la media de 41.840 reales. Por otro lado, las tierras apenas aparecen en la mitad de los inventarios de este sector, constituyendo un $15,26 \%$ de los activos y alcanzando una limitada media de 18.180 reales.

Entre las pattidas de bienes muebles destaca la de capital, con un $21,55 \%, y$ que se traduce en un promedio de 25.694 reales por inventario, cantidad que solamente superan los labradores. Resulta significativo, que los comerciantes jerezanos presenten mayores activos en productos agrarios, media de 14.154 reales, que en mercancías diversas, con una media de 8.949 reales. Ello se debe, especialmente a la preponderancia de la actividad agrícola en Jerez y, en concreto, a la comercialización de los vinos. En esta línea deberíamos incluir los 2.784 reales de media en pertrechos, principalmente en tonelería. En cuanto al confort, aunque relativamente destacable, con un promedio de 6.384 reales, se encuentra por debajo del que presentan hasta otras cuatro categorías socioprofesionales analizadas.

El pequeño número de transportistas, 7 , el $1,96 \%$ de la muestra, acumula unos activos de 214.296 reales, que corresponden a un mínimo $0,5 \%$ de todos los activos inventariados. Por tanto, las fortunas de estas personas, que vemos por partidas en el gráfico 7, son muy reducidas, presentando una media de 30.614 reales, sólo superior a las que tienen la gente del campo y los indeterminados. El $71,4 \%$ de estos transportistas se sitúan en los niveles de entre 10.001 y 50.000 reales.

Como ocurría con los comerciantes, grupo con el que comparte similitudes, hay una gran equidad entre bienes inmuebles, con el 52,35\%, y muebles, con el 
$47,65 \%$. Un dato a destacar, no poseen tierras y, por lo tanto, todas las propiedades inmuebles son edificios, las viviendas y cuadras del ganado, que alcanzan un valor promedio de 16.024 reales.

Los bienes muebles más significativos son las cabezas de ganado, bueyes y mulas que utilizan para el desarrollo de su actividad económica, las cuales representan una media de 4.836 reales en las fortunas. Más considerable aún, es la partida de capital, con gran incidencia de las deudas a favor, alcanzando los 6.895 reales de promedio. Las otras cantidades son insignificantes, resaltando, por lo que nos ilustra la frugalidad de la vida de estos hombres, los 696 reales de media de la partida de confort.

Y terminamos el sector terciario comentando las fortunas de los profesionales liberales y personal de la administración (incluidos tres eclesiásticos). Este heterogéneo grupo está conformado por 21 individuos, el 5,88\% del total. La suma de sus activos se sitúa en 1.250 .373 reales, un $2,94 \%$ de todo lo inventariado, resultando una media de 59.541 reales por persona. El gráfico 8 nos muestra la distribución por partidas.

Esta categoría socioprofesional presenta un rasgo común con los labradores, los bienes muebles predominan, con un $55,32 \%$, sobre los inmuebles, que llegan al $44,68 \%$. Entre estos últimos, las tierras tienen una presencia testimonial, con el 7,58\%, dando lugar a un promedio de 4.517 reales, mientras que son las viviendas, con el $37,1 \%$, las que constituyen la partida más destacada de las fortunas, alcanzando una media de 22.084 reales.

En el análisis de los bienes muebles se observa la heterogeneidad ya mencionada que registran los componentes de este grupo, ya que, aunque con cantidades infimas, aparecen en todas las partidas. Pero tan sólo destacan las referidas al capital, con un $29,3 \%$ y un promedio de 17,447 reales por inventario, y al confort, que representa un $14,12 \%$ y da lugar a una media de 8.403 reales por persona.

Los hacendados, sin actividad económica conocida, pero claramente diferenciados de los indeterminados tanto por la estructura como por la cuantía de sus fortunas, forman con sus 18 casos, el 5,04\% del total, una categoria, eminentemente social, concreta. Sus activos son cuantiosos, 3.128.482 reales, lo que implica el 7,36\% del global inventariado, y una fortuna media de 173.801 reales, cantidad sólo superada por labradores y vitivinicultores. El $50 \%$ de sus componentes se encuentra en los niveles de activos de entre 50.001 y 250.000 reales. La distribución por partidas queda reflejada en el gráfico 9 . 
El predominio vuelve a corresponder a los bienes inmuebles, con el $60,3 \%$, frente al $39,7 \%$ de los bienes muebles. El mayor peso de las propiedades inmuebles viene dado no tanto por la detentación de tierras, que liega al $13,62 \%$ del conjunto de los activos con un promedio de 23.668 reales, sino gracias a la posesión de edificios, que llegan a constituir casi la mitad de sus fortunas, el $46,68 \%$, siendo su valor medio de 81.133 reales, el más alto de todos los grupos estudiados, logrando concentrar el $13,25 \%$ del valor acumulado de la partida de edificios.

En cuanto a las partidas muebles incidir en la insignificancia de los porcentajes relativos a todo lo que implique la participación en alguna actividad económica, concentrándose los activos en el capital, con un $22,44 \%$ y un promedio de 38.998 reales, el segundo en magnitud inmediatamente detrás del de los labradores, y en el confort, con un $16,04 \%$ y una media de 27.871 reales por individuo, cantidad no superada por ninguna otra categoría socioprofesional y que nos viene a indicar que son los hacendados los que viven en un ambiente de mayor comodidad y lujo. Así, acaparan hasta el 18,26\% del montante global de la partida de confort.

Para terminar, nos queda el grupo de los indeterminados, el más amplio de todos con 90 individuos, el $25,22 \%$ del total, pero el de menor incidencia económica, ya que su 1.224.361 reales de activos sólo representa el 2,88\% del global inventariado, y, lo que es más esencial, una fortuna media de 13.604 reales, la menor que presentan todas las categorías analizadas. El reparto de los activos se muestra en el gráfico 10 .

Aqui, el predominio de los bienes inmuebles, con un $90,08 \%$, es absoluto, quedando el 9,92\% restante para los bienes muebles. La significación de los bienes raíces no se debe a las tierras, que proporcionan tan sólo un $12,3 \%$ al total de las fortunas, sino a las viviendas que poseen casi todos los elementos de esta categoría, que acumulan el $77,78 \%$ del global de sus activos, con un promedio de 10.580 reales. Las partidas muebles no sólo presentan minúsculas cuantías sino que, además, el número de individuos contabilizados en cada una de ellas nunca supera el 25\% de los miembros del grupo. Los indeterminados se nos muestran como gentes con mínimos recursos, muchas veces mujeres, que, al menos, disfrutan de vivienda propia.

Hasta aquí, el análisis general y por categorías sociales, del cual se desprenden las siguientes conclusiones sobre la sociedad de Jerez de la Frontera en la segunda mitad del siglo XVIII.

1. Si situamos el nivel de riqueza, con todo lo que ello implica de status de vida, ostentación, reconocimiento social y posibilidades de inversión, en una canti- 
dad inventariada de 100.000 reales, nos encontramos en Jerez con tres grupos en los que, mayoritariamente, sus elementos presentan fortunas por encima de la mencionada cantidad. Se trata, y por este orden, de los labradores, los vitivinicultores y los hacendados. Salvo en este último grupo, en el que predominan las propiedades y las rentas generadas pasivamente por éstas, nos hallamos ante los sectores socioeconómicos más dinámicos de la población jerezana.

2. Aunque el estudio global de la estructura de las fortunas incidía en la primacía de los bienes muebles sobre los inmuebles, el análisis pormenorizado de los distintos grupos nos descubre una realidad diferente, ya que en todas las categorías socioeconómicas, a excepción de labradores y profesionales liberales, son las propiedades inmuebles las que predominan. Era precisamente la fuerte incidencia en el conjunto de los dichos labradores, con sus partidas de cosecha y ganado, la que originaba la falsa percepción.

3. Dada la fuerte vinculación a la que estaban sometidas las tierras, son los edificios, viviendas y bodegas, los bicnes inmuebles que acaparan la mayor parte de los procesos de inversión de capitales. Salvo en los casos de labradores y viticultores, en los restantes el valor de los edificios significa entre el 35 y el $78 \%$ de la cuantía de las fortunas. Es más, la importancia de la posesión de un edificio, esencialmente la vivienda, es tal que, en gran media, viene a determinar la realización del propio inventario. Es un bien que aparece en el $88 \%$ de las particiones $y$, por ejemplo, en el grupo de los indeterminados representa, en bastantes casos, la única partida inventariada. En cierta forma, podemos decir que el tener una vivienda se convierte en el signo diáfano del abandono, la sali$\mathrm{da}$, de situaciones de precariedad. No conviene olvidar que en este estudio no aparecen ni se contabilizan los que nada poseen.

4. Las tierras, tal como ya hemos dicho, no son un bien demasiado presente en los inventarios. No obstante, a excepción de los transportista, todos los grupos, en mayor o menor cuantía, presentan posesiones rústicas, lo que las convierte en un elemento a tener en cuenta en los procesos de inversión. Pero, quiénes invierten preferentemente en tierras. Sin olvidar a los labradores, cuya presencia resalta más por las cantidades aplicadas que por el número de individuos que las realizan, y las gentes del campo, cuyas inversiones en tierras son fuertes en proporción a sus propios activos pero escasas en relación al conjunto, son viticultores y vitivinicultores los que sobresalen en este aspecto. No cabe duda de que nos encontramos en una fase cronológica de expansión del viñedo, y son los sectores socioeconómicos relacionados con esta actividad, aquellos que se dedican al cultivo de la vid o la transformación y comercialización de los vinos obteniendo buenos beneficios por ello, los más interesados en coadyuvar al mencionado crecimiento y, a la vez, a la ampliación de sus negocios. 
5. En una sociedad, como la del Antiguo Régimen, donde la descapitalización, la falta de numerario, es una peculiaridad dominante, la presencia de capital, ya sea como dinero líquido o como deudas cobrables, resulta un elemento que marca, claramente, diferencias. Por un lado, su posesión, aunque sea en cuantía mínima, en una población que de forma mayoritaria vive en la pobreza, en el día a día, implica un status de vida, al menos, desahogado y la posibilidad de resistir situaciones de crisis (periodos sin trabajo, incrementos del precio de las subsistencias,...). En este sentido, hasta los indeterminados de nuestro estudio, los que tienen menores fortunas, alcanzan un promedio de 630 reales en la partida de capital. Mientras que artesanos, transportistas y profesionales liberales acumulan en el mencionado asiento entre un 20 y un $30 \%$ de sus activos. Por otro lado, estarian aquellas categorías socioprofesionales en las que el capital no sólo esta presente sino que, además, alcanza cuantías altamente significativas. En esta situación estarían, y por este orden, labradores, comerciantes, hacendados y vitivinicultores, con promedios que van desde los 56.000 reales de los primeros a los 25.000 de los últimos. Nuestro estudio nos ha permitido exteriorizar la funcionalidad de los capitales de estos grupos. Así, la mayor parte de estos activos estaría invertida en deudas a favor o préstamos, entre el $43 \%$ que registran los labradores y el $72 \%$ al que llegan los vitivinicultores. Este último caso en concreto estaría relacionado con los adelantos de dinero a cambio de asegurarse la adquisición de las cosechas de los pequeños cultivadores del viñedo. Otra porción, mucho más reducida del capital, entre el $6 \%$ que marcan los vitivinicultores y el $24 \%$ en los hacendados, se encontraba aplicada en deuda fija, preferentemente censos hipotecarios. Por último, queda un tercer fragmento del capital que se mantiene como dinero en efectivo. En este aspecto, los hacendados, con el $14 \%$, y los vitivinicultores, con el $22 \%$, son poco relevantes. Pero, la situación de los labradores, que llegan al $40 \%$, y de los comerciantes, con hasta el $42 \%$, es bien distinta y de difícil explicación a la luz de los datos que manejamos. ¿Por qué estas importantes cantidades sin aplicación?. ¿Eran necesarias como reserva para el normal desarrollo de sus actividades económicas?. ¿Se trataba de ahorro acumulado a la espera de una posible inversión a medio o largo plazo?. O, ¿estamos ante simples mecanismos de atesoramiento?

6. La riqueza, la situación económica próspera, no sólo hay que tenerla sino demostrarla. Por ello, la partida de confort, con sus distintos apartados, resulta esclarecedora de la estratificación social jerezana. ¿Cuándo podemos decir que una persona ha alcanzado un nivel adecuado de bienestar, de comodidad? ¿Cuándo que vive en el lujo?. Estas cuestiones son bastante subjetivas y difíciles de delimitar. Intentaremos una aproximación relacionando datos cuantitativos y cualitativos. Así, consideramos que, en el Jerez de la segunda mitad del 
siglo XVIII, una casa estaba bien provista de muebles y ajuar, cuando el valor inventariado de estos bienes era superior a los 3.000 reales. Del mismo modo, una familia vivía cómodamente cuando, en esta partida de confort, sobrepasaba los 7.500 reales. Y, finalmente, aquellos que excedieran de los 25.000 reales serían los que se encontraran en una posición de lujo u opulencia. Al aplicar este baremo a los distintos grupos socioprofesionales, buscando la generalidad y no la casuística, obtenemos que los indeterminados, la gente del campo, los viticultores y los transportistas ni siquiera entranán en la primera opción. En la que sí podemos ubicar a los artesanos y a los comerciantes, éstos debido a la incidencia de los componentes del comercio minorista. En el nivel de comodidad se hallarían los vitivinicultores y los profesionales liberales. Predominado los hacendados y, especialmente, los labradores en la tercera opción, la del lujo. Así, de los 23 que se hallan en dicha situación, hay 10 labradores, 5 hacendados, 3 vitivinicultores, 2 profesionales liberales, 2 comerciantes y 1 viticultor. Pero hemos dicho que la opulencia no sólo es una cuestión contable, sino, de forma muy destacada, de apariencia. $Y$ el análisis de los inventarios nos lo corrobora, ya que entre éstos que viven en el lujo están: los 8 que tienen oratorios; 10 de los 13 que disfrutan de carruajes; 11 de los 20 que poseen libros; y 17 de los 22 que gozan de joyas valoradas en más de 4.000 reales.

7. La economía de Jerez, a la vista de los datos aportados por los inventarios, muestra un predominio, casi exclusivo, de las actividades agricola-ganaderas. El sector artesano-industrial se nos presenta bastante débil, no sólo por el número de individuos contabilizados sino, sobre todo, por la descripción que se ofrece de sus talleres, donde no se aprecian innovaciones técnicas y en los que sigue imperando un utillaje tradicional, escaso, sencillo y de mínimo valor. El sector comercial en su conjunto, excluido el tráfico de los productos agricolas, tampoco presenta un mejor panorama, y un solo dato resulta esclarecedor: el valor de la cosecha del principal labrador duplica al de todos los géneros existentes en las tiendas y almacenes de los comerciantes. Todos los números ponderan, pues, la significación de la actividad agrícola-ganadera. Su atractivo, dígase posibilidad de beneficios, no se duda cuando hasta componentes de los artesanos, comerciantes y profesionales liberales participan en ella. Pero, por supuesto, son los labradores y, en menor proporción, vitivinicultores, viticultores y gente del campo, los grupos que prevalecen e, incluso, monopolizan las labores agricolas y la ganadería de Jerez. $Y$ es el desarrollo de su actividad económica el que está situando en la cabeza de la sociedad jerezana, tal como venimos señalando, a labradores y vitivinicultores.

Para concluir, el estudio de los inventarios post-morten nos descubre los cambios que se están produciendo en la segunda mitad del siglo XVIIl en el seno 
de las más importantes agrociudades andaluzas, en este caso concreto en la de Jerez de la Frontera. Las tradicionales familias potentadas, oligarcas, en parte reflejadas en los hacendados de nuestro análisis, siguen manteniendo posiciones de privilegio, de ostentación, basadas en la posesión de bienes inmuebles, generalmente vinculados, que, por una parte, las sostienen pero, por otra, las maniatan y les limitan su capacidad de acción para adaptarse, si esa fuera su voluntad, a los nuevos mecanismos económicos. Grupos sociales comolos artesanos y los comerciantes de los que se esperaba, al menos de los últimos, que encabezaran los procesos de transformación de la sociedad, no tienen ni la fuerza numérica ni, sobre todo, económica, para desarrollar dicho papel. Finalmente, aparecen determinados cuerpos socioprofesionales, muy ligados a las actividades agrícola-ganaderas, en un momento de expansión de las mismas, que tras obtener una privilegiada o, al menos, holgada situación económica y un cierto reconocimiento por parte de la población, demandan, sino cambios radicales, si una readaptación de la sociedad de tal manera que su posición se vea sensiblemente mejorada. Los vitivinicultores y, de forma destacada, los grandes labradores, dueños o arrendatarios de tierras, son los protagonistas jerezanos de estas demandas. Muchos aspectos históricos de fines del siglo XVIII y de las primeras décadas de la centuria decimonónica, tales como la desamortización civil y eclesiástica, los ataques al régimen señorial y su abolición, la apertura de los gobiernos municipales y el fin de las regidurías perpetuas, el proteccionismo agrícola en un contexto de liberalismo económico, etc., no responden tanto a las apetencias de una burguesía financiera y comercial ideal, sino que, más bien, se explican en esa línea de demanda de readaptación socioeconómica propugnada, desde las medianas y grandes localidades, por estos nuevos o renovados poderosos de la tierra.

Este trabajo está dedicado a la memoria del profesor José Luis Pereira Iglesias, compañero que se nos fue y al que difícilmente podremos olvidar. Antes de su marcha pudo leer esta aportación, muy en la línea de investigaciones suyas, y asesorarme sobre algunas modificaciones convenientes. Gracias por todo. 
Cuadro 4. Distribución de inventarios por categoría socioprofesional según nivel de activos

\begin{tabular}{|l|c|c|c|c|c|c|c|c|c|c|c|c|}
\hline Activo (en reales) & $\mathbf{0 4 0}$ & $\mathbf{0 4 1}$ & $\mathbf{0 1 1}$ & $\mathbf{0 1 2}$ & $\mathbf{0 1 3}$ & $\mathbf{0 1 4}$ & $\mathbf{0 2 1}$ & $\mathbf{0 3 1}$ & $\mathbf{0 3 2}$ & $\mathbf{0 3 3}$ & Total inventarios & \% Total inventarios \\
\hline $1-10.000$ & 50 & 1 & 0 & 3 & 0 & 18 & 3 & 1 & 1 & 4 & 81 & 22,69 \\
$10.001-25.000$ & 28 & 0 & 0 & 11 & 0 & 25 & 5 & 6 & 2 & 5 & 82 & 22,97 \\
$25.001-50.000$ & 9 & 5 & 0 & 16 & 2 & 13 & 6 & 6 & 3 & 3 & 63 & 17,65 \\
$50.001-100.000$ & 3 & 2 & 10 & 10 & 5 & 8 & 4 & 6 & 1 & 5 & 54 & 15,12 \\
$100.001-250.000$ & 0 & 7 & 6 & 4 & 7 & 1 & 1 & 7 & 0 & 4 & 37 & 10,36 \\
$250.001-500.000$ & 0 & 1 & 13 & 1 & 6 & 0 & 0 & 1 & 0 & 0 & 22 & 6,16 \\
$500.001-1.000 .000$ & 0 & 2 & 9 & 0 & 1 & 0 & 0 & 0 & 0 & 0 & 12 & 3,36 \\
+ de 1.000 .000 & 0 & 0 & 4 & 0 & 0 & 0 & 0 & 20 & & 0 & 6 & 1,68 \\
\hline Total inventarios & 90 & 18 & 42 & 45 & 21 & 65 & 19 & 29 & 7 & 21 & 357 & 100,00 \\
\hline$\%$ Sobre total & 25,22 & 5,04 & 11,76 & 12,60 & 5,88 & 18,21 & 5,32 & 8,12 & 1,97 & 5,88 & 100,00 & 100,00 \\
\hline
\end{tabular}

\section{Notas:}

$\begin{array}{lllll}\text { 040: indeterminado; } & \text { 041: hacendado; } & \text { 011: labrador; } & \text { 012: viticultor; } & \text { 013: vitivinicultor; } \\ \text { 014: campo; } & \text { 021: artesanos; } & \text { 031: comercio; } & \text { 032: transporte; } & \text { 033: profesionales. }\end{array}$


Cuadro 5. activos acumulados por categoría socioprofesional según nivel de activos

\begin{tabular}{|l|c|c|c|c|c|c|c|c|c|c|}
\hline Activo (en reales) & $\mathbf{0 4 0}$ & $\mathbf{0 4 1}$ & $\mathbf{0 1 1}$ & $\mathbf{0 1 2}$ & $\mathbf{0 1 3}$ & $\mathbf{0 1 4}$ & $\mathbf{0 2 1}$ & $\mathbf{0 3 1}$ & $\mathbf{0 3 2}$ & $\mathbf{0 3 3}$ \\
\hline $1-10.000$ & 277.449 & 6387 & 0 & 19.228 & 0 & 125.207 & 21.218 & 8.382 & 5.163 & 30.225 \\
$10.001-25.000$ & 434.611 & $\mathbf{0}$ & $\mathbf{0}$ & 204.216 & 0 & 417.708 & 77.303 & 98.938 & 39.181 & 88.170 \\
$25.001-50.000$ & 332.821 & 183.414 & 0 & 542.875 & 74.342 & 446.365 & 222.295 & 215.564 & 116.443 & 107.084 \\
$50.001-100.000$ & 179.480 & 139.174 & 748.527 & 709.896 & 333.612 & 606.573 & 268.926 & 462.987 & 53.509 & 385.813 \\
$100.001-250.000$ & 0 & 1.115 .827 & 905.344 & 534.011 & 1.193 .869 & 150.726 & 120.743 & 784.102 & 0 & 639.081 \\
$250.001-500.000$ & 0 & 252.618 & 4.746 .239 & 404.646 & 1.896 .430 & 0 & 0 & 274.549 & 0 & 0 \\
$500.001-1.000 .000$ & 0 & 1.431 .008 & 5.689 .319 & 0 & 592.442 & 0 & 0 & 0 & 0 & 0 \\
+ de 1.000 .000 & 0 & 0 & 7.456 .119 & 0 & 0 & 0 & 0 & 6.334 .603 & 0 & 0 \\
\hline Activo acumulado & 1.224 .361 & 3.128 .428 & 19.545 .548 & 2.414 .872 & 4.090 .695 & 1.746 .579 & 710.485 & 8.179 .125 & 214.296 & 1.250 .373 \\
\hline \% sobre total & 2,88 & 7,36 & 45,98 & 5,68 & 9,62 & 4,11 & 1,67 & 19,24 & 0,50 & 2,94 \\
\hline
\end{tabular}


GRÁFICO 1. ACTIVO DE LOS LABRADORES POR PARTIDAS EN \%

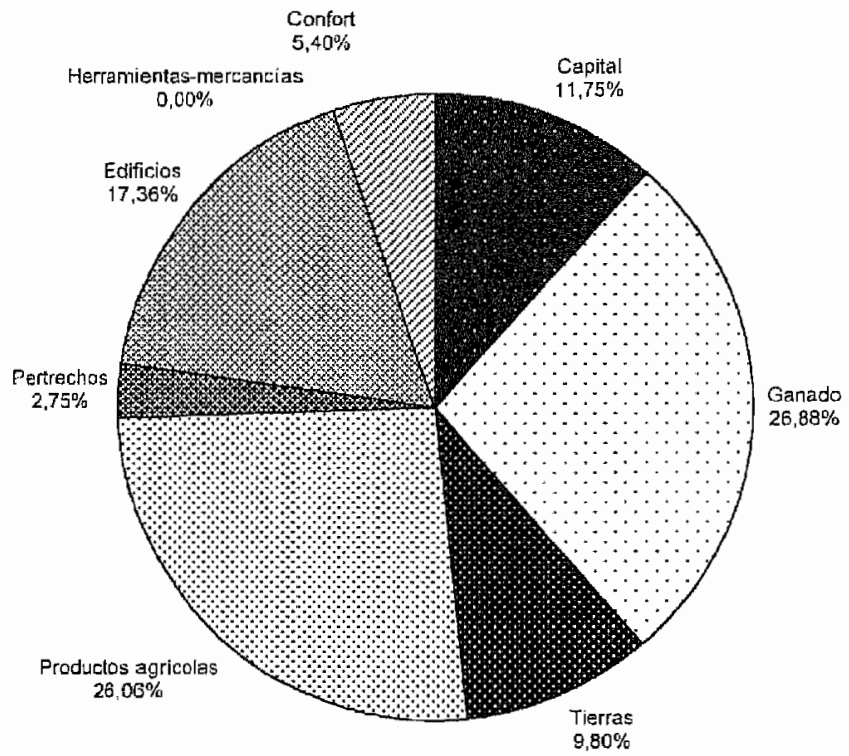

GRAFICO 2. ACTIVO DE LOS VITICULTORES POR PARTIDAS EN \%

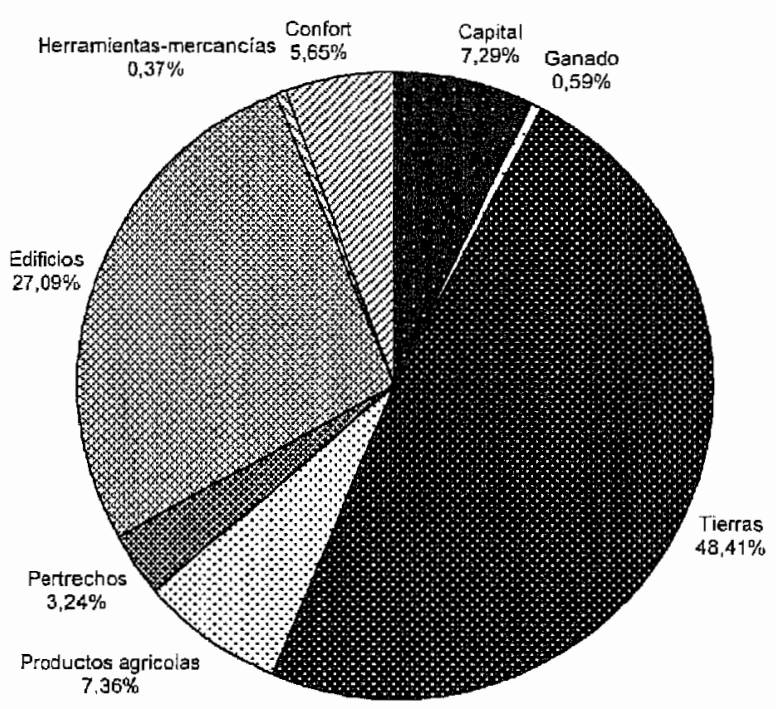


GRÁFICO 3. ACTIVO DE LOS VITIVINICULTORES POR PARTIDAS EN \%

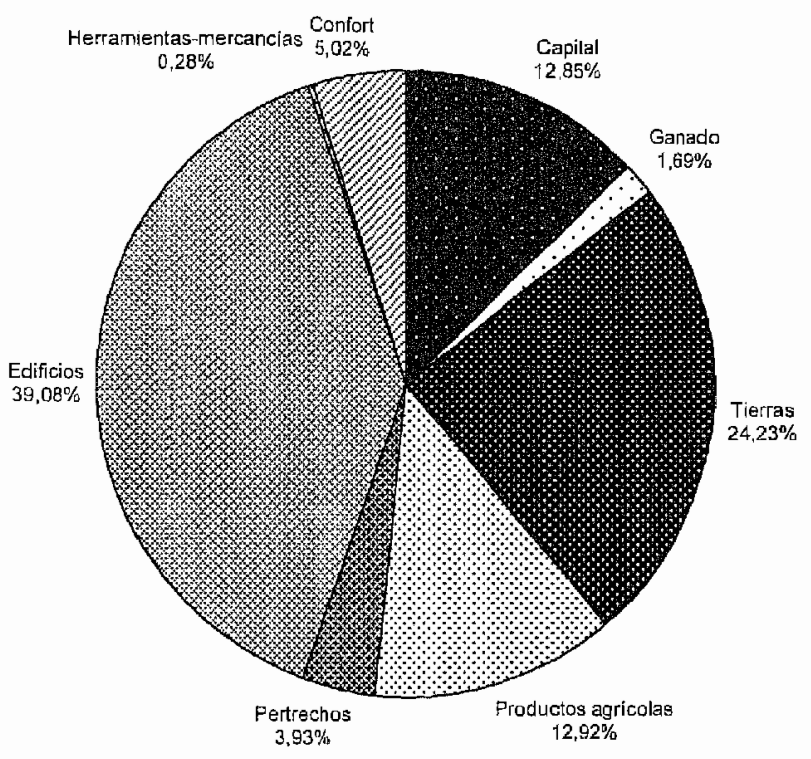

GRÁFICO 4. ACTIVO DE LA GENTE DE CAMPO POR PARTIDAS EN \%

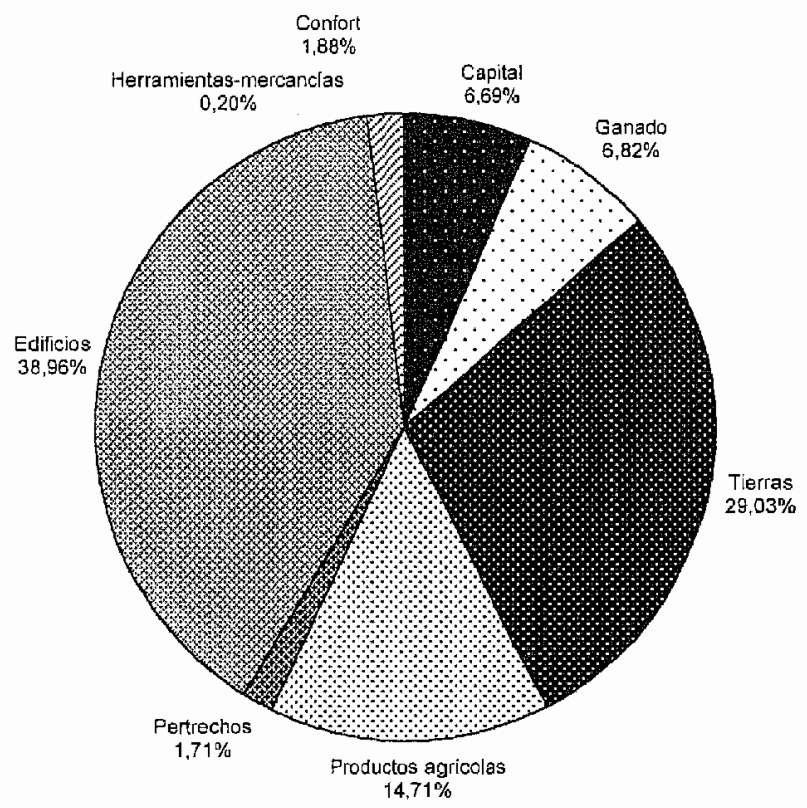


GRAFICO 5. ACTIVO DE LOS ARTESANOS POR PARTIDAS EN \%

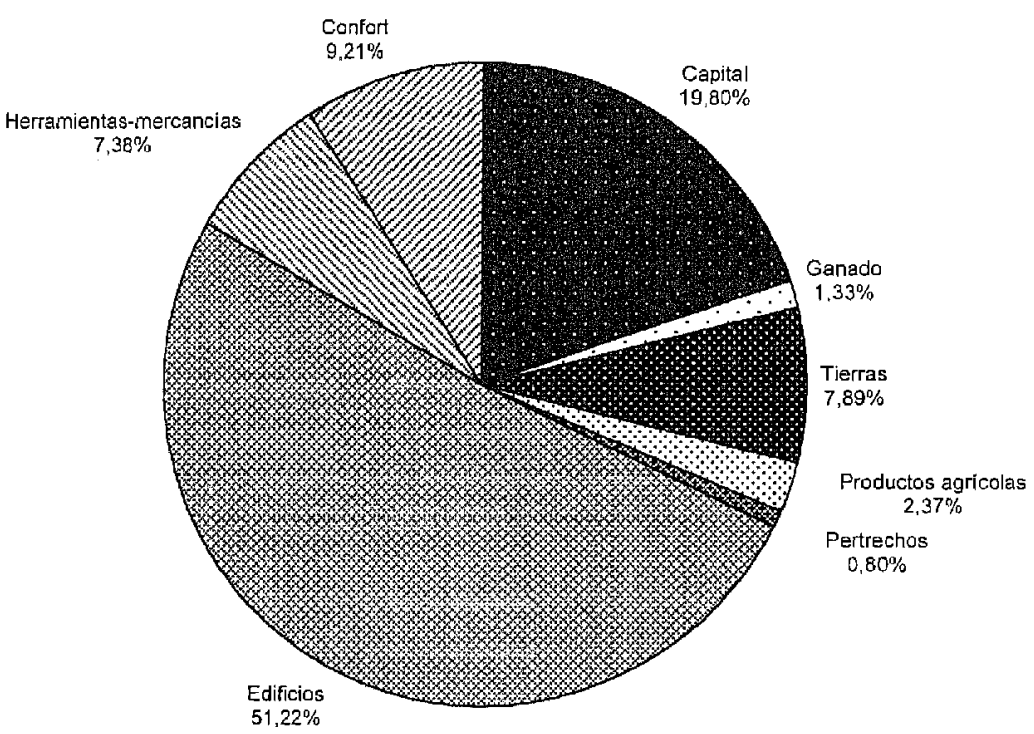

GRÁFICO 6. ACTIVO DE LOS COMERCIANTES (sin El sr. ROY) POR PARTIDAS EN

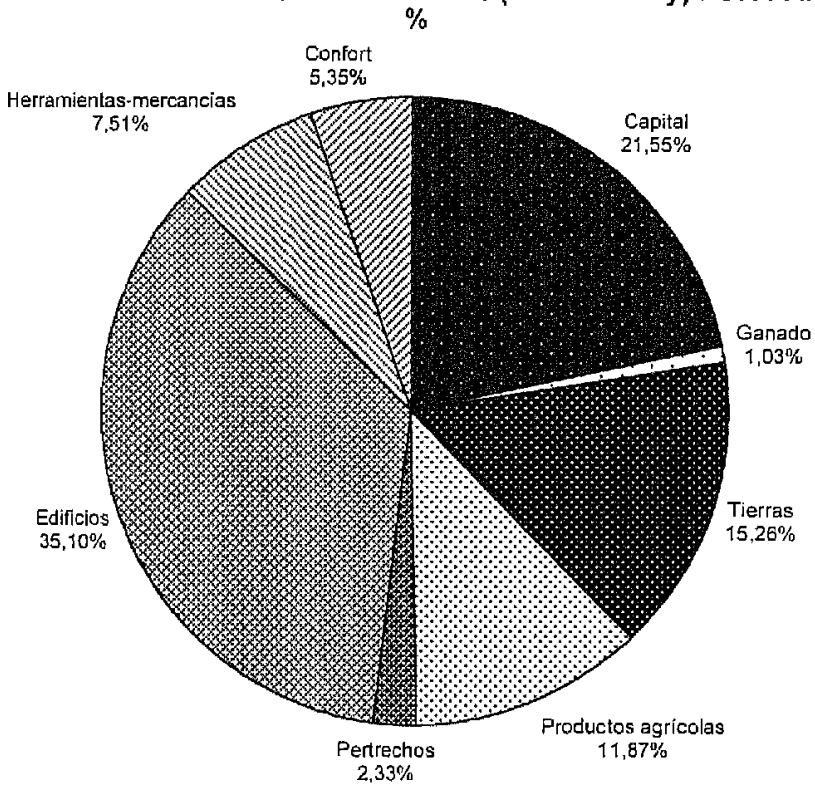




\section{GRÁFICO 7. ACTIVO DE LOS TRANSPORTISTAS POR PARTIDAS EN \%}

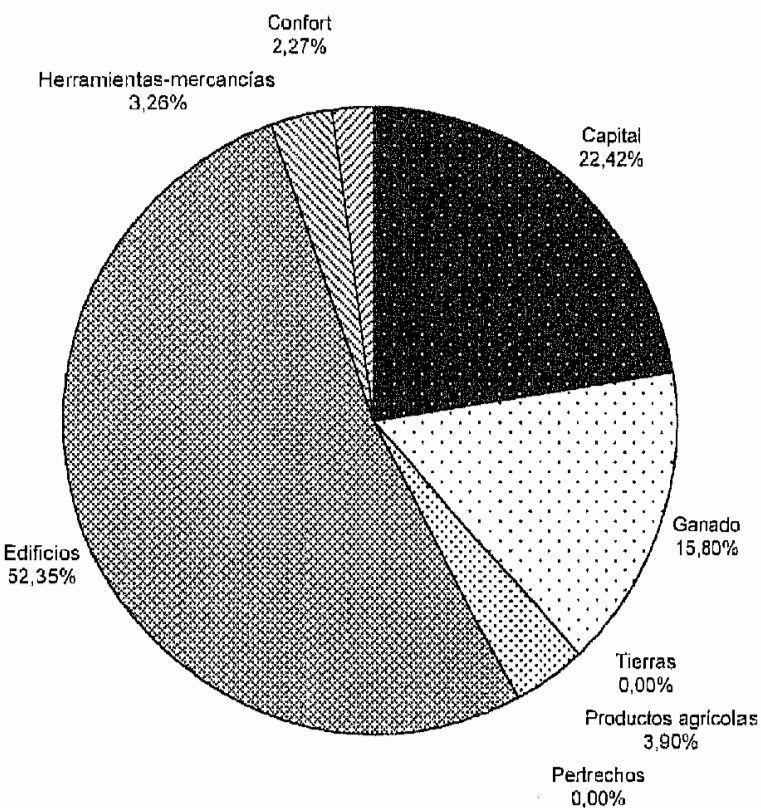

GRÁFICO 8. ACTIVO DE LOS PROFESIONALES POR PARTIDAS EN \%

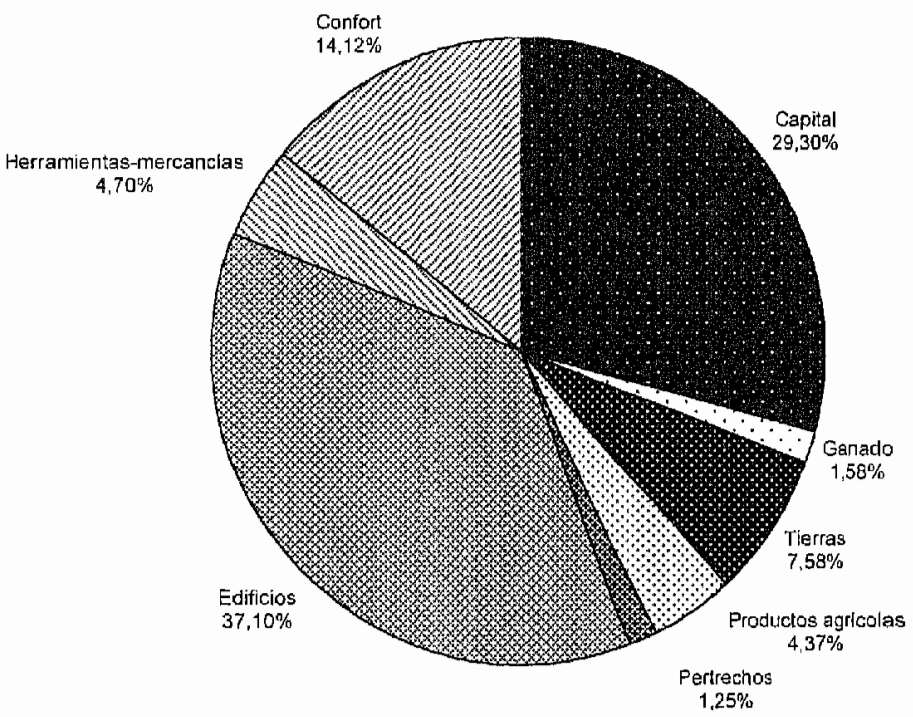


GRÁFICO 9. ACTIVO DE LOS HACENDADOS POR PARTIDAS EN \%

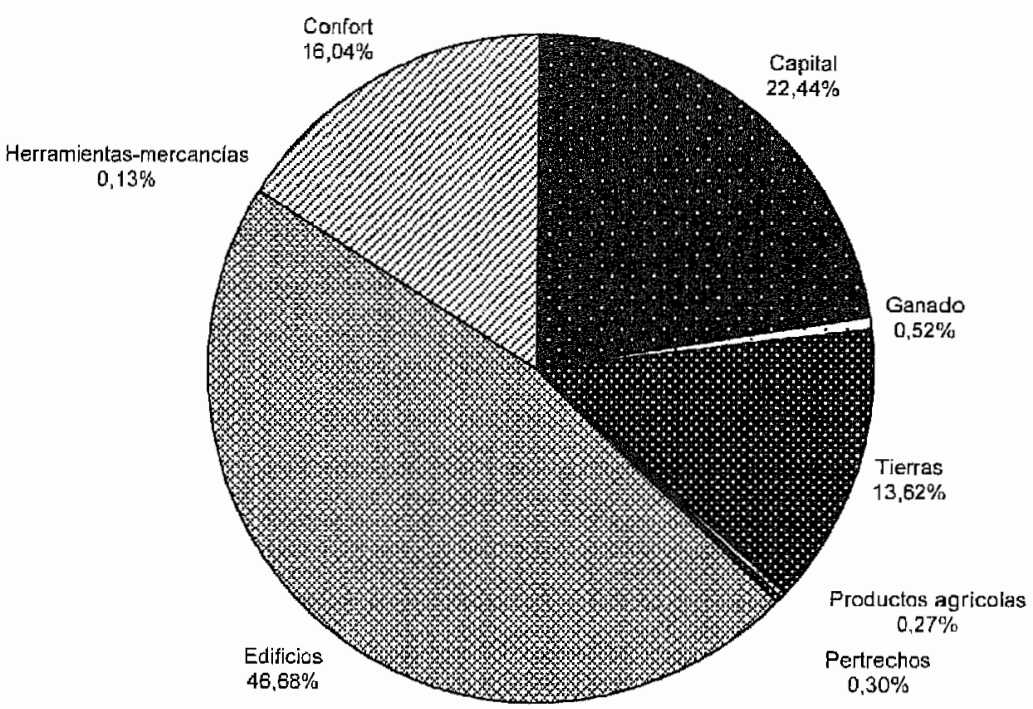

GRÁFICO 10. ACTIVO DE LOS INDETERMINADOS POR PARTIDA EN \%

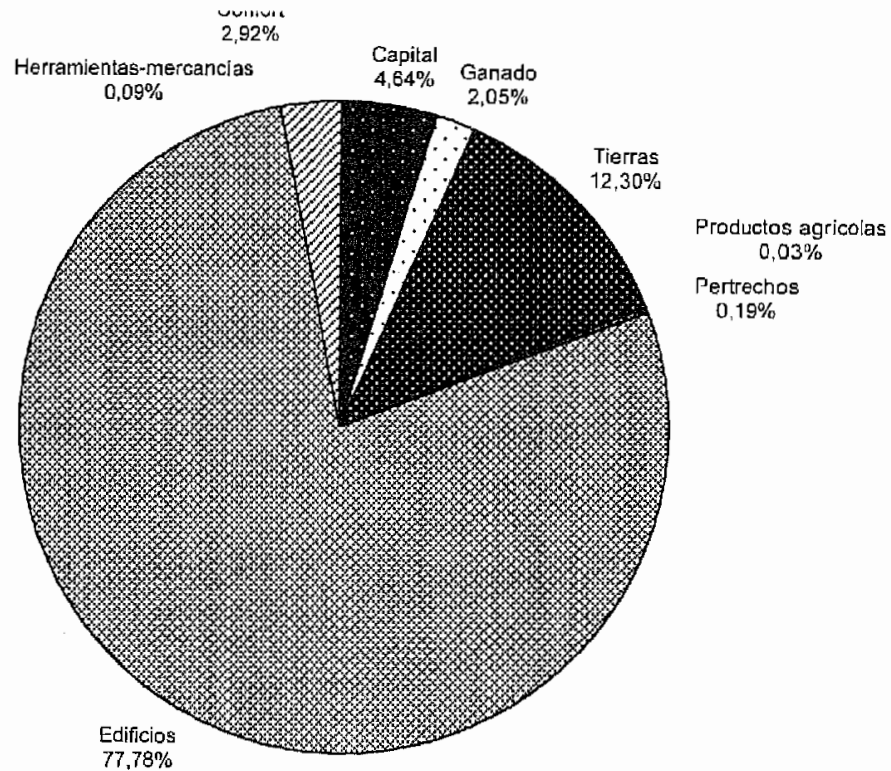

